\title{
WestVirginiaUniversity
}

THE RESEARCH REPOSITORY @ WVU

Graduate Theses, Dissertations, and Problem Reports

2006

\section{An economic analysis of food stamp participation in West Virginia}

Ahadu T. Tekle

West Virginia University

Follow this and additional works at: https://researchrepository.wvu.edu/etd

\section{Recommended Citation}

Tekle, Ahadu T., "An economic analysis of food stamp participation in West Virginia" (2006). Graduate Theses, Dissertations, and Problem Reports. 4276.

https://researchrepository.wvu.edu/etd/4276

This Thesis is protected by copyright and/or related rights. It has been brought to you by the The Research Repository @ WVU with permission from the rights-holder(s). You are free to use this Thesis in any way that is permitted by the copyright and related rights legislation that applies to your use. For other uses you must obtain permission from the rights-holder(s) directly, unless additional rights are indicated by a Creative Commons license in the record and/ or on the work itself. This Thesis has been accepted for inclusion in WVU Graduate Theses, Dissertations, and Problem Reports collection by an authorized administrator of The Research Repository @ WVU. For more information, please contact researchrepository@mail.wvu.edu. 


\title{
An Economic Analysis of Food Stamp Participation in West Virginia
}

\author{
Ahadu T. Tekle \\ Thesis submitted to the \\ Davis College of Agriculture, Forestry, and Consumer Sciences \\ at West Virginia University \\ in partial fulfillment to the requirements \\ for the degree of \\ Master of Science \\ in \\ Agricultural and Resource Economics \\ Tesfa G. Gebremedhin, Ph.D. Chair \\ Mark Sperow, Ph.D \\ Tom McConnell, Professor \\ Agricultural and Resource Economics Program \\ Division of Resource Management
}

Morgantown, West Virginia

2006 


\title{
ABSTRACT \\ An Economic Analysis of Food Stamp Participation in West Virginia
}

\begin{abstract}
Ahadu T. Tekle
Poverty and food insecurity are challenging socio-economic problems that policy makers are trying to address for a long time. Among other things, providing financial and in-kind assistance are some of the initiatives taken to improve food security for low income households. Food Stamp Program is an important assistance program that serves to meet this goal. The objective of this study is to examine the implication of economic and policy variables on food stamp participation in West Virginia. To understand the current and lagged impact of economic variables on current food stamp participation, static and dynamic econometric models are used. These models are estimated using panel data of West Virginia counties. Results indicate that county poverty, unemployment, and the cost of living directly affect the level of county food stamp participation; while employment growth and PRWORA welfare policy tend to reduce county level food stamp program participation.
\end{abstract}




\section{ACKNOWLEDGEMENT}

I am mostly indebt to Dr. Tesfa G. Gebremedhin, committee chair, for his caring guidance, active involvement, and constant assistance throughout my study as well as my major advisor for my thesis. I would also like to thank my committee members, Dr. Mark Sperow and Professor Tom McConnell for their insightful suggestions, constructive criticism, and support.

I am most appreciative of the opportunity to further my education at West Virginia University. The financial support from the Division of Resource Management, NRAC, Social Justice, and the Extension Service and the dedicated faculty and staff in the Agricultural and Resource Economics Program were extremely valuable and helpful in my study.

I wish to thank my parents, brothers, and sisters for their encouragement and support. I would like also to thank Yohannes Hailu for his constant support and encouragement throughout my study and in the completion of my thesis.

I would also like to express my gratitude to all my friends, fellow students, the staff and faculty for their friendship and help and to Dr. Tesfa's family members and Gebremeskel Habteyonas for their moral support and encouragement.

This thesis is dedicated to my parents and Yohannes Hailu. 


\section{TABLE OF CONTENTS}

Abstract

Acknowledgements

ii

List of Tables

vi

List of Figures

\section{CHAPTER 1: INTRODUCTION}

1.1. Introduction

1.2. Background Information

1.3. Problem Statement

1.4. Objectives

1.5. Hypothesis.

1.6. Approach

1.7. Organization of the study

\section{CHAPTER 2: LITERATURE REVIEW}

2.1. Background of the Food Stamp Program $\quad 10$

2.2. Food Stamp Eligibility and Benefit 13

2.2.1. Program Eligibility 13

2.2.2. Program Benefits $\quad 14$

2.3. Historical Trend of Food Stamp Program Participation 16

2.3.1 Food Stamp Program Participation Rate among Subgroups 17

2.3.2. Food Stamp Program Entry and Exit $\quad 19$

2.4. Trends in Food Stamp Caseloads (1994-2000) 22

2.5. Food Stamp Participation and Food Insufficiency 25

2.6. Food Stamp Expenditure and the Economy 29

CHAPTER 3: THORETICAL BASIS FOR FOOD STAMP PARTICIPATION DECISIONS

3.1. Food Stamp Program Participation Decision 33

3.2. Cost and Benefit of Food Stamp Program Participation 34

3.3. Theoretical Model of Food Stamp Program Participation 36

\section{CHAPTER 4: EMPIRICAL MODELING OF FOOD STAMP PARTICI PATION}

4.1. Model Specification $\quad 47$

4.1.1. Static Model $\quad 50$

4.1.2. Dynamic Model 52

4.2. Method of Estimation 54

4.3. Types and Sources of Data 
CHAPTER 5: EMPIRICAL RESULTS AND ANALYSIS

5.1. Estimation Procedures $\quad 60$

5.2. Results and Analysis $\quad 64$

5.2.1 Static Model Results 64

5.2.2 Dynamic Model Results 69

\section{CHAPTER 6: SUMMARY AND CONCLUSION}

6.1. Summary and Conclusion 75

6.2. Limitations and Suggestions for Future Research 78

$\begin{array}{ll}\text { REFERENCE } & 79\end{array}$

$\begin{array}{lc}\text { APPENDIX } & 85\end{array}$ 


\section{LIST OF TABLES}

Table 2.1 Gross and Net Income Eligibility Standard, Effective October 2004 to September 2005

Table 2.2 Maximum Benefit per Family Size from Oct 2004-Sept 2005

Table 2.3 Rate of Food Stamp Participation (1976-002)

Table 2.4 FSP Rate, Number of Eligible Individuals and Participating Individuals among Subgroups (1994-2002)

Table 4.1 Sources of Data

Table 5.1 Static Model Empirical Results

Table 5.2 Dynamic Model Empirical Results. 


\section{LISTS OF FIGURES}

Figure 1.1 Food Stamp Program participants, Unemployed Individuals and Individuals Live in Poverty (1985-2003)

Figure 3.1 Figure 3.1. Indifference Curve of a Household not Using Food Stamps

Despite being Eligible for Participation

Figure 3.2 . Indifference Curve of a Household that Does Not Exhaust the Entire Food Stamp Benefit

Figure 3.3 Indifference Curve of a Household that Exhausts the Food Stamp Benefit but Does Not Spend Income to Purchase Additional Food

Figure 3.4 Indifference Curve of a Household that Allocates Income to Purchase Additional Food 


\section{CHAPTER 1}

\subsection{INTRODUCTION}

Despite the fact that the United States is one of the wealthiest nations, poverty-related malnutrition has been a long-standing social and economic challenge for researchers and policy makers. The number of people living in poverty has been increasing for the past years in the United Sates. According to U.S. Census Bureau report of 2005, the

percentage of people live in poverty was $12.1,12.5$ and 12.7 percent in year 2002, 2003 and 2004, respectively.

Meeting nutritional needs is particularly difficult for poor families. In 2004, 11.9 percent of all U.S. households were "food insecure" because of lack of resources. Of the 13.5 million households that were food insecure, 4.4 million suffered from food insecurity that was so severe that they were classified as "hungry" (Nord et al., 2005). Food insecure households were uncertain of having or unable to acquire a supply of food sufficient to meet basic needs at all times because of inadequate resources (Winicki et al. ,2002). Since 1999, food insecurity has increased by 3 million households. In 2004, 38.2 million people lived in households experiencing food insecurity, compared to 33.6 million in 2001 and 31 million in 1999.

The high costs of housing, health care, and medical care coupled with low earnings create pressure on families who live on limited incomes. Among the household expenditures, the budget allocated to food is relatively more flexible than other expenses such as housing and medical expenses; thus, most likely food is often the first expense to be cut. 
Since the mid-1940s, the U.S. Government has been committed to ensuring that its citizens neither go hungry nor suffer the consequences of inadequate dietary intake. For the past decades policy makers attempted to address the problem of low income households by introducing numerous assistance programs to improve the lives of lowincome households. The Food Assistance Program, Aid to Families with Dependent Children (AFDC), Supplemental Security Income (SSI), and Medicaid Program, are some of the assistance programs introduced to assist low income families. These programs have been a security for low-income households by providing financial and in kind assistance.

Currently there are fifteen food assistance programs administered by USDA aimed at improving the nutrition of low-income households. In the year 2004, the total expenditure of USDA for food assistance programs totaled $\$ 46$ billion, of which the Food Stamp Program (FSP), the National School Lunch Program, the Special Supplemental Nutrition Program for Women, Infant and Children (WIC), the School Breakfast Program, and Child and Adult Care Program, were accounted for 94 percent of the total expenditure. During this time, the total federal funding for the FSP was \$27 billion, which was 59 percent of all domestic nutrition assistance funding. In 2005, more that 25 million Americans were receiving monthly food stamp (FS) benefits, a 40 percent increase since the start of 2000 (The Food Assistance Landscape, 2005).

The FSP played a significant role in improving the well-being of a significant number of children who live in low-income households. According to the USDA reports for the past years, children (below age of 18) accounted for more than half of food stamp 
benefits. For examples, in 2000, 8.8 million children received food stamp benefits out of the 17.1 million persons who lived in low-income households that participated in food stamp program (Winicki et al., 2002).

\subsection{BACKGROUND INFORMATION}

Food stamps are crucial to helping low-wage working families make ends meet. For example, a family of four supported by a full time, year-round minimum wage worker, will fall short of the poverty line by 25 percent (even after counting the earned income tax credit) if the family does not receive food stamps. Food stamps increase the typical monthly purchasing power of such a family by 39 percent (Center on Budget and Policy Priorities, 2000 a). Although the Food Stamp Program is not designed to reduce child poverty, food stamps do augment the purchasing power of low-income households and can improve the well-being of people living in poverty (Jolliffe et al., 2005).

The health of the general economy affects the food assistance programs. FSP participation tends to follow the unemployment rate, which is a key indicator of the health of the general economy. During economic downturn, FSP participation tends to increase as unemployment increases and income decreases (Hanson and Golan, 2002). On the other hand, during economic expansion, FSP participation tends to decrease as the employment rate and income rise. Hanson and Gundersen (2002) argued that general economic conditions influence the number of people that participate in the FSP. As household's income increases, either fewer households are eligible for FSP participation or the level of FS benefits for eligible households declines. The general state of the economy influences the expectation of the individuals about their prospects regarding employment and income and, therefore, influences their decision to participate in the 
FSP. Good economic conditions create the expectation of increased income, better employment opportunities, and future benefits hence, eligible households may be less likely to participate in the program (McKernan and Ratcliffe, 2003).

FSP participation showed fluctuation over the years. As indicated in figure 1.1 the average number of FSP participants declined slowly from 1986-1989, however it grew substantially during the early 1990s. The average FSP participation declined through 2000 since the peak in 1994, but began to rise in 2001. As illustrated in the figure unemployment and FSP participation follow similar trend, however, sometimes they diverge. For example between the years of 1992-1994, the average number of unemployed individuals declined but the average number of FSP participants increased. Similarly between 2002 and 2003, the average number of FSP participants was raising but the average number of unemployed individuals was declining. 
Figure 1.1 Food Stamp Program participants, Unemployed Individuals and Individuals Living in Poverty (1985-2003)

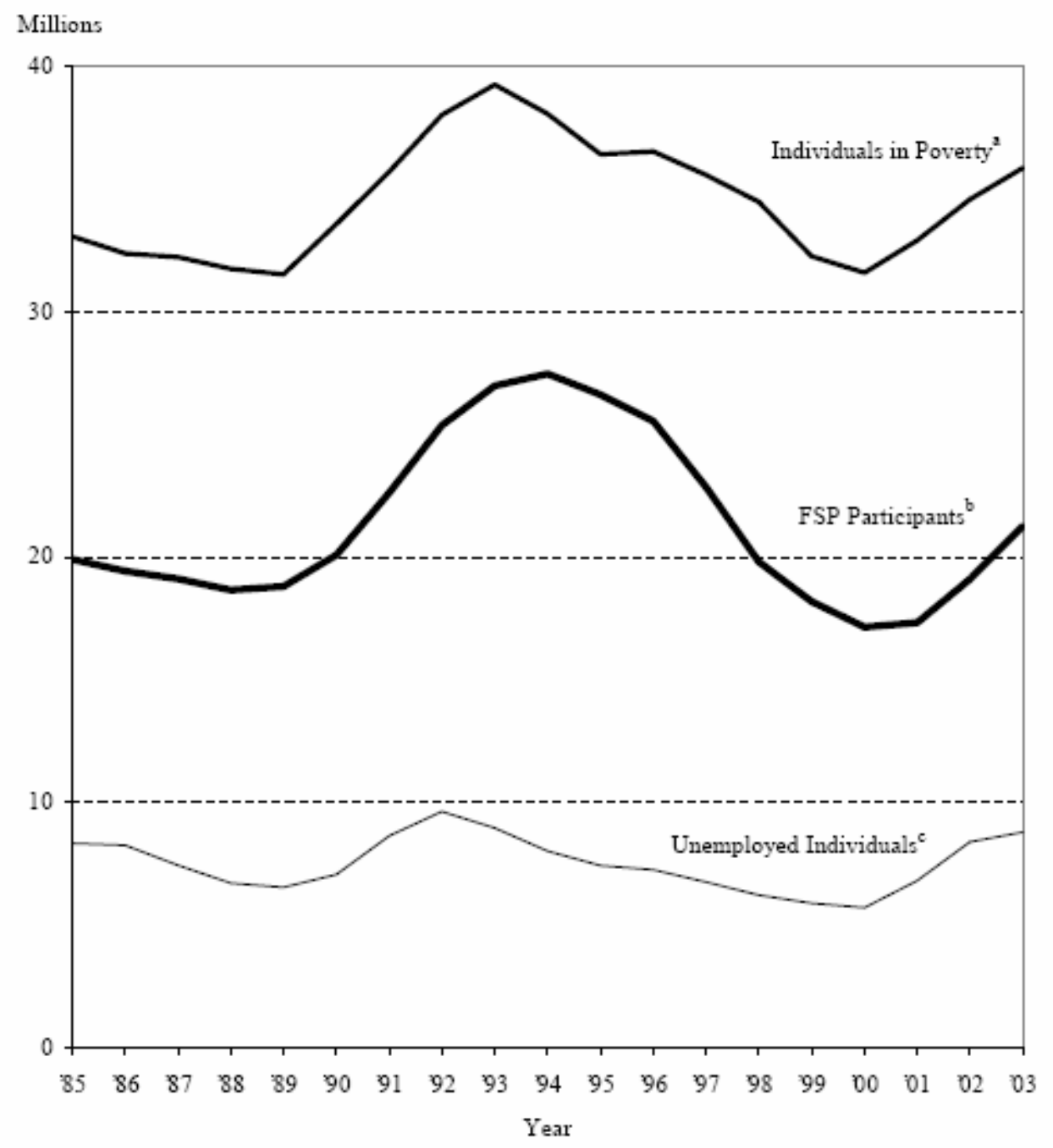

\footnotetext{
anmual values. Source: Bureau of the Census, Poverty in the United States: 2003.

bAverage monthly values. Source: Food and Nutrition Service.

'Average monthly values. Source: Bureau of Labor Statistics.
}

Similarly, FSP participation and poverty it closely related. As illustrated in the above figure, both had similar trend from 1985-2003 except in 1993, where the average number of FSP participants rise despite the average number pf people live in poverty declined.

\footnotetext{
${ }^{1}$ Source: Cunnyngham and Brown, 2004
} 


\subsection{PROBLEM STATEMENT}

West Virginia is one of the nation's poorest states. Many parts of the state continue to experience high unemployment, a shrinking economic base, deeply rooted poverty, low human capital formation, and out-migration (Deavers and Hoppe, 1992). West Virginia ranks second to last in per capita income and lags the nation and the rest of the Appalachian region in almost every other indicator measuring income, employment, and wealth, making it a classical example of persistent poverty (Dilger and Witt, 1994; Haynes, 1996; Maggard, 1990; U.S. Census Bureau, 2000 a). Slow income and employment growth, out-migration, and the disappearance of rural households, are causes and effects of persistently declining public services and high rates of poverty. Lagging economic development negatively affects the economic and social well-being of West Virginia's rural population and the ability of local governments to provide basic social services (Cushing and Rogers, 1996). These realities have not changed much in recent years. Recently, West Virginia has experienced very low level of per-capita income, sluggish economic growth, very low level of educational attainment compared to other states, loss of non-farm jobs and a rising unemployment rate (WV Economic Outlook, $2001 ; 2002 ; 2003 ; 2004 ; 2005)$.

West Virginia has the fourth highest poverty rate following New Mexico, Louisiana and Mississippi. For the last four consecutive years the poverty rate was more than 16 percent higher than the national average rate of 12.4 percent. According to the American Community Survey Report (2005), in 2004, 371,000 people (around 20.4 percent of the population) live in poverty in West Virginia. The poverty rate is even higher for children below the age of 18 . According to the same report 70,000 children 
(24.4 percent) under the age of 18 were living in poverty in 2004. However, little research has been done on the relationship between FSP participation and macroeconomic indicators and policy change at the state level. The main focus of this study is to examine the FSP participation and its relationship with demographic, economic characteristics and policy factors in West Virginia.

\subsection{OBJECTIVES}

The overall objective of this study is to examine the pattern of food assistance participation and its relationship to demographic characteristics, economic development and policy implications in West Virginia. The specific objectives are to:

1. Determine the relationship between food assistance participation and macro economic indicators such as employment, unemployment, Income, poverty level and price index, and policy measures.

2. Draw relevant policy implications from the empirical findings and analysis of the study.

\subsection{HYPOTHESIS}

Based on economic theory and previous study results, it is expected that the explanatory variables will have the following hypothesized relationships with FSP participation:

Hypothesis 1: County employment growth (or decline in unemployment rate) reduces the proportion of county population dependent on food stamps.

Hypothesis 2: Counties experiencing increase in per capita income face declining FSP participation. 
Hypothesis 3: A rise in poverty rate in a county increases the proportion of county population participating in the FSP.

Hypothesis 4: A rise in the cost of living (measured by the consumer price index) in the economy increases FSP participants.

Hypothesis 5: The Personal Responsibility and Work Opportunities Reconciliation Act (PRWORA) is effective in reducing county FSP participants.

\subsection{APPROACH}

The study employs both static and dynamic econometric models to determine the relationship between county socio-economic conditions and food stamp caseloads. Static models enable the determination of economic relationships at a point in time. This property of static models allows the use of comparative static properties to study the relationship between dependent and independent variables at a particular point in time.

Dynamic models help in understanding the relationship between variables over a period of time. In these models, the pattern of relationship among current and lagged variables over a number of years is established for empirical analysis.

\subsection{ORGANIZATION OF THE STUDY}

Chapter One includes the problem statement, background information, objective of the study, approach and organization of the study. Chapter Two provides an extensive literature review on the relationship between food stamp and economic and demographic factors. In Chapter Three, the theoretical background of individual decision to participate in the program is presented with the description of variables. Chapter Four illustrates the 
model of estimation. Chapter Five the presents empirical estimation procedures and analysis of research result. Chapter Six summarizes the results, provides some conclusions, and addresses some limitation of the study and suggestion for future research. 


\section{CHAPTER 2}

\section{LITERATURE REVIEW}

\subsection{BACKGROUND OF THE FOOD STAMP PROGRAM}

The first U.S. food assistance program was established during the depression of 1930s. The goal of the food assistance program was to stabilize farm prices and incomes. The government purchased surplus agricultural products from producers and redistributed to the poor and, therefore, kept farm prices and incomes from declining. During the 1960s, the assistance program became independent of the farm assistance program and focused on the food and nutritional need of the society (Kuhn et al., 1996).

The Food Stamp Program began as a small pilot program in 1961. The program expanded during the 1960s and early 1970s, and finally reached nationwide coverage in 1975. The Food Stamp Act of 1964 introduced the first coupon-based system which allowed program participants to buy a variety of food with coupons rather than restricting their consumption to surplus commodities. Participants purchased food stamp coupons for an amount based on income and household size and would receive some free "bonus stamp" (Fox et al., 2004).

With the introduction of National eligibility standards in 1971, all states were required to inform low income households about the availability of food stamps. Due to the concern of low participation in the food stamp program, in 1977 the requirement of the household to purchase food stamp coupons with cash was eliminated. Under this act households would receive fewer coupons but did not pay for them. However, the 
elimination of the purchase requirement of coupons did not change the net dollar value of the subsidy received by the household (Kuhn et al., 1996).

Direct changes to the FSP during 1980-98 were comparatively modest. In 1981, the Omnibus Budget Reconciliation Act (OBRA 81) and the FS and Commodity Distribution Amendments of 1981 for the first time applied the gross income eligibility standards to all households not including aged or disabled members. The Farm Security Act of 1985 raised the asset limit to $\$ 2,000$ for non-elderly households and to $\$ 3,000$ for elderly households. In 1988, the Hunger Prevention Act reduced the maximum food stamp allotment incrementally from 200 percent to 103 percent of the Thrifty Food Plan. The Thrifty Food Plan, developed by USDA, serves as a national standard for a nutritious diet at low cost. It represent a set of market baskets of food that people of specific age and gender consume at home to maintain a healthy diet that meets dietary standards, by taking into consideration the food consumption pattern of U.S households. The cost of the meal plan for each category of gender and age is calculated based on average national food prices adjusted inflation. Furthermore, the cost of the market basket for a household is adjusted by the size of the household (Nord, 2005).

In 1996, the Personal Responsibility and Work Opportunity Reconciliation Act (PRWORA) was enacted. PRWORA was the most significant social welfare legislation with direct and indirect implication on Food Stamp Program. PRWORA introduced a 3 month benefit limit in every 36 months for able-bodied individuals (between the ages of 18-49) without dependents who are not working or participating in approved workrelated programs at least for 20 hours. The Act also restricted eligibility of most legal immigrants except for some refugees, military personnel on active duty, naturalized 
citizens, permanent resident aliens, veterans or their spouses. Moreover, the act gave states power to reduce or eliminate food stamp benefits upon the failure of the adult in the household to comply with the rules of other public assistance programs (Wilde et al., 2000). The act also reduced maximum food stamp benefit from 103 percent to 100 percent of Thrifty Food Plan. The Act also terminated the Aid to Families with Dependent Children (AFDC) and replaced it with Temporary Assistant for Needy Families (TANF), a new block grant (a financial aid package that grants federal money to state and local governments for use in social welfare programs) to fund state welfare programs.

The FSP has undergone significant regulatory and legislative changes since the enactment of PRWORA. Some of the changes are aimed to reverse the previous rules and others are directed to increase states' flexibility in their program administration. In 2002, the Food Security and Rural Investment Act of 2002 was enacted. The major changes included: restoration of eligibility to qualified aliens who have been in United States at least for five years, restoration of eligibility for immigrants receiving certain disability payment and for children regardless of their stay in the country, and it removed time limits on FS eligibility for refugees and people who granted asylum. The Act provides options for the states to simplify the program, adopt a simplified reporting system and providing transitional benefits for clients leaving TANF. Moreover, the Act modified the standard deduction applied to income when determining benefit, so that the deduction is scaled to family size and indexed to inflation (Mathematica Policy Research Inc., 2003). 


\subsection{FOOD STAMP ELIGIBILITY AND BENEFIT}

Food Stamps provide resources for individuals to buy certain food items from stores. The items that can be bought with food stamps include: food items from stores and meals prepared and served by authorized meal delivery service. However, medicines, vitamins, alcoholic beverages, cigarettes, pet food, non food items such as paper products and household supplies cannot be purchased with food stamps.

\subsubsection{Program Eligibility}

Not all low-income households are eligible for benefits from the FSP. There are certain financial and work-related requirements households must meet to be eligible for the FSP. Financial criteria include the gross income test, the net-income test, and the asset test.

A household's gross income before taxes in the previous month must be at or below 130 percent of the federal poverty line to meet the gross income criteria. However, households with any member over the age of 60 or disabled are exempted from gross income test. In addition to these tests, households must have net monthly income at or below 100 percent of the federal poverty line to pass the net income test for eligibility. The maximum gross and net income that different household size should earn to qualify in the program is indicated in Table 2.1. In addition, income-eligible households must have liquid asset less than $\$ 2,000$ to qualify in the program $(\$ 3,000$ for the households with someone over age of 60 and households with a disabled member, as of 2002). However, in the determination of eligibility the value of a residence, personal property, earned income tax credit payments, life insurance, and pension assets, are excluded. Work related eligibility conditions require able-bodied household members to register for 
work, accept suitable job offers, and comply with State welfare agency work for training programs (Fox et al., 2004).

Table 2.1. Gross and Net Income Eligibility Standard, Effective October 2004 to September 2005.

\begin{tabular}{ccc}
\hline Household Size & $\begin{array}{c}\text { Gross monthly income } \\
(130 \text { percent of poverty })\end{array}$ & $\begin{array}{c}\text { Net monthly income } \\
(100 \text { percent of poverty })\end{array}$ \\
\hline 1 & 1,009 & 776 \\
2 & 1,354 & 1,041 \\
3 & 1,698 & 1,306 \\
4 & 2,043 & 1,571 \\
5 & 2,387 & 1,836 \\
6 & 2,732 & 2,101 \\
7 & 3,076 & 2,366 \\
8 & 3,421 & 2,631 \\
Each additional & +345 & +265 \\
member & & \\
\hline \multicolumn{2}{l}{ Source: USDA, Food and Nutrition Service } \\
\end{tabular}

However, some groups are categorically ineligible for the FSP whether or not they fulfill all the requirements for eligibility. These include, for example, people who are not citizens or permanent residents, postsecondary students, and people living in institutional settings. However, households in which all members receive Temporary Assistance for Needy Families (TANF), Supplementary Security Income (SSI), or general assistance are exempted from both the income and asset test (Kornfeld, 2002)

\subsubsection{Program Benefits}

Eligible households are issued a monthly allotment of food stamps based on the Thrifty Food Plan, the national standard established by USDA for determining the low-cost nutritious diet for different household size. The amount of food stamp benefit the household receives varies by size of the household and is subject to annual adjustment for

\footnotetext{
${ }^{2}$ http://www.fns.usda.gov/fsp/faqs.htm\#13
} 
the changes in the cost of the Thrifty Food Plan. An individual household's food stamp allotment is equal to the maximum allotment for that household's size determined by thrifty plan less 30 percent of the household's net income. For example households with no countable income receive $\$ 393$ per month in Fiscal Year 2005 for a household of four people, the maximum allotment for this household size. Table 2.2 shows the maximum amount of food stamp benefit for different family sizes as of October 2004 to September 2005.

Table 2.2. Maximum Benefit per Family Size from Oct 2004-Sept 2005

\begin{tabular}{lccccccccc}
\hline $\begin{array}{l}\text { Number in } \\
\text { Household }\end{array}$ & 1 & 2 & 3 & 4 & 5 & 6 & 7 & 8 & $\begin{array}{c}\text { Each additional } \\
\text { person }\end{array}$ \\
\hline $\begin{array}{l}\text { Maximum } \\
\text { monthly benefit }\end{array}$ & 149 & 274 & 393 & 499 & 592 & 711 & 786 & 898 & +112 \\
\hline
\end{tabular}
Source: USDA, Food and Nutrition Service ${ }^{3}$

The amount of FS benefit alloted for a given household size is uniform across the United States. All participants receive the same level of benefits based on their income, regardless of their geographic location (except in Alaska, Hawaii, and the Virgin Islands where benefit levels are higher because of higher food prices).

Historically, FS benefits were issued in the form of paper coupons. FS recipients used these coupons for food at authorized stores. In 1996, PRWORA mandated that all FS benefits be distributed via electronic transfers; therefore, FS benefits are now paid through Electronic Benefit Transfer (EBT), an ATM-like card used to make food purchases at grocery stores by deducting the purchase amount from the recipient's monthly food stamp amount. The use of EBT card is expected to help enhance security and reduce the stigma often associated with receiving food stamp benefits. EBT system

\footnotetext{
${ }^{3}$ http://www.fns.usda.gov/fsp/faqs.htm\#13
} 
became operational in all states at different time. For instance, only two counties of West Virginia adopt this technology in 2002 and by 2003, all counties started to distribute benefits via the EBT card.

\subsection{HISTORICAL TREND OF FOOD STAMP PROGRAM PARTICIPATION}

The FSP participation rate "the percentage of eligible people who actually participate in the FSP" is an important measure of how well the program is reaching its target population. Not all of those who are eligible participate in the program as some choose not to participate, while others are not aware that they are eligible.

Table 2.3 Rate of Food Stamp Participation (1976-2002)

\begin{tabular}{lcc}
\hline & \multicolumn{2}{c}{ Participation Rate (\%) } \\
\hline Year & Individuals & Households \\
September 1976 & 31.1 & 32.6 \\
February 1978 & 38.3 & 37.8 \\
August 1980 & 55.2 & 52.5 \\
August 1982 & 52.2 & 51.5 \\
August 1984 & 51.8 & 51.6 \\
August 1986 & 47.6 & 46.5 \\
August 1988 & 48.1 & 47.1 \\
August 1990 & 54.2 & 54.9 \\
August 1991 & 57.0 & 59.1 \\
August 1992 & 59.3 & 61.6 \\
August 1993 & 60.3 & 64.0 \\
August 1994 & 61.4 & 64.6 \\
September 1994 & 74.8 & 69.6 \\
September 1995 & 72.7 & 69.2 \\
September 1996 & 69.2 & 65.1 \\
September 1997 & 64.0 & 57.5 \\
September 1998 & 59.8 & 54.2 \\
September 1999 & 57.9 & 53.0 \\
FY 1999 & 56.2 & 51.7 \\
FY 2000 & 55.7 & 50.1 \\
FY 2001 & 53.2 & 48.0 \\
\hline FY 2002 & 53.8 & 48.3 \\
\hline
\end{tabular}

Source: FS Program Operations Data. FSPQC (Food Stamp Program Quality Control) Data, and CPS Data for the year the years shown. 
Based on the data reported in Table 2.3, individual participation rates increased substantially in the late 1970 s, from 31 percent in 1976 to 55 percent in 1980. FSP participation rates then leveled off, declining slightly to 48 percent by 1988 . Through the late 1980s and early 1990s, FSP participation rates rose rapidly, peaking in 1994 before beginning a seven-year decline. Similarly household participation increased significantly in late 1970s from 33 percent to 53 percent in 1984. Household participation dramatically declined between 1986 and 1988, and substantially increased after 1990 until 1996. Participation declined each year after 1997 until 1999 and started to rise until 2002 as shown in table 2.3 .

\subsubsection{Food Stamp Program Participation Rate among Subgroups}

FSP participation rates vary by demographic and economic subgroups. Historically, participation rates have been relatively high for individuals in households with very low incomes, children and TANF and Supplemental Security Income (SSI) recipients. Conversely, participation rates have been relatively low for households with elderly member (Cunnyngham, 2004).

According to (Mathematica Policy Research Inc., 2003), the majority (54 percent) of food stamp recipients was households with children in 2002. Of these households, 63.6 percent were single parent households, 17.6 percent were headed by married parents, and 10.8 percent had no members over the age of 17 participating in the FSP (the remaining 8.0 percent were other multiple adult households with children). Households with the elderly member represented 18.7 percent of all food stamp households. Over threequarters of them (80.2 percent) lived alone and received an average monthly benefit of 
$\$ 50$. Households containing the elderly and other individuals, either elderly or nonelderly, received an average benefit of $\$ 121$. Over one-quarter (27 percent) of food stamp households contained disabled individuals. Of these households, over half (58.7 percent) lived alone, receiving an average benefit of $\$ 50$. Households with the disabled and others, either disabled or non-disabled, received an average benefit of $\$ 187$. Households without children, elderly, or disabled adults, received an average benefit of $\$ 122$. Households with multiple non-elderly, non-disabled adults and no children received an average benefit of \$201. Participation rates for different household characteristics for the period of 1994 to 2002 are depicted in Table 2.4.

Table 2.4. FSP Rate, Number of Eligible Individuals and Participating Individuals among Subgroups (1994-2002)

\begin{tabular}{|c|c|c|c|c|c|c|c|c|c|}
\hline & 1994 & 1995 & 1996 & 1997 & 1998 & 1999 & 2000 & 2001 & 2002 \\
\hline Individuals in All Households & 74.8 & 72.7 & 69.2 & 64.0 & 59.8 & 57.9 & 59.3 & 53.2 & 53.8 \\
\hline \multicolumn{10}{|l|}{ Age of Individuals } \\
\hline Children & 89.6 & 86.8 & 85.6 & 75.7 & 70.7 & 67.9 & 71.8 & 69.1 & 70.3 \\
\hline Non-elderly Adults (18-59) & 74.2 & 71.2 & 68.7 & 65.8 & 60.3 & 58.1 & 59.9 & 49.4 & 49.9 \\
\hline Elderly Individuals & 35.7 & 36.1 & 29.7 & 29.8 & 30.9 & 32.9 & 30.7 & 28.1 & 26.9 \\
\hline Disabled Non-Elderly Individuals & 49.0 & 53.6 & 49.0 & 54.1 & 52.5 & 59.3 & 53.1 & 44 & 46 \\
\hline Non-Disabled Childless Adults Subject to Work & 47.7 & 41.3 & 37.0 & 40.1 & 24.4 & 24.9 & 27.1 & 19.3 & 20 \\
\hline \multicolumn{10}{|l|}{ Registration } \\
\hline Non-citizens & 66.8 & 66.0 & 64.5 & 77.7 & 63.0 & 49.4 & 44.7 & 37.2 & 43.7 \\
\hline Citizen Children Living with Non-citizen Adults & 80.5 & 59.8 & 58.3 & 38.7 & 39.3 & 45.6 & 38.1 & 37.2 & 43.7 \\
\hline $\begin{array}{l}\text { Individual in Households Without Any Non-citizens } \\
\text { or Non-disabled Childless Adults Subject to Work } \\
\text { Registration }\end{array}$ & 76.0 & 75.9 & 72.3 & 63.8 & 61.4 & 60.4 & 61.8 & 57.0 & 57.9 \\
\hline \multicolumn{10}{|l|}{ Household Composition } \\
\hline Households with Children & 87.2 & 84.4 & 82.7 & 74.6 & 69.8 & 67.1 & 70.7 & 64.7 & 65.4 \\
\hline Single-Parent & 98.9 & 100.8 & 96.3 & 86.3 & 84.6 & 81.4 & 90.7 & 93.8 & 96.1 \\
\hline Married Couple & 67.6 & 61.6 & 62.1 & 62.1 & 52.3 & 45.6 & 47.1 & 44.1 & 44.7 \\
\hline Other Multiple Adults & 89.0 & 73.6 & 75.2 & 78.1 & 67.3 & 73.7 & 67.0 & 41.4 & 39.2 \\
\hline Children Only & 78.1 & 62.9 & 80.3 & 36.6 & 36.6 & 44.5 & 39.9 & 46.3 & 56.5 \\
\hline Households without Children & 45.8 & 45.3 & 40.3 & 40.6 & 38.6 & 39.4 & 38.0 & 32.9 & 33.2 \\
\hline
\end{tabular}

Source: FS Program Operations Data. FSPQC (Food Stamp Program Quality Control) Data, and CPS Data for the year the years shown.

The FSP participation rate for the elderly (over the age of 60) has been generally low for the last decade. Based on FS Program Operation and CPS (Current Population 
Survey) data participation rate was 36 percent in 1994 and fell to 27 percent in 2002. Similarly, participation rate of non-elderly adults were 74 percent in 1994 and fell to 50 percent in 2000. The Household Characteristics Survey conducted in 2000 also supports the report of USDA 2002 regarding low participation rate of elderly as reported by Gunderson and Oliveira (2001). According to the result of the survey, out of the total participants, only 5 percent of the benefit is accounted by the household headed by 60 years of age or older. Households with some of its members over the age of 60 years are less likely to be food insufficient than average households; therefore, these low levels of food insufficiency appear to influence their low participation rate (Gunderson and Oliveira, 2001).

FSP participation for children generally had been higher than the other age groups. For the period between 1994 and 2002, participation was the highest in 1994 and lowest in 1999, 90 and 68 percent, respectively as indicated in table 2.4. Moreover the table indicated that over half of the total participants were children. More than half of the eligible non-elderly adults (18-59 years) had been participating from 1994 to 2002. Based on FS Program Operation and CPS data, Hanson and Gundersen (2002) reported that the participation rates in 1999 and 2000 were 58 and 60 percent, respectively.

\subsubsection{Food Stamp Program Entry and Exit}

It is a common phenomenon that FSP participants leave the program and re-enter again more than once in their life time. Rank and Hirschl (2003) noted that participating in the eligible food stamp program is very common for both children (age 1-20) and working age-adults (20-59). Their result indicated that 49 percent of the eligible children have 
received food stamps at some point by the time they reached 20 years of age, and 51 percent of eligible adults participated in FSP sometime between 20 and 65 years of age.

Re-entry in FSP is a common practice. Gleason et al. (1998) indicated that more than half of those who left FSP re-entered within two years. They also found that two third of the new participants are previously used food stamps, which suggests that individuals who had previously received food stamps are more likely to enter the program in a given month than those who had never received food stamps. Using 1990 and 1991 Survey of Income and Program participation (SIPP) data they found that about two thirds of all people who entered the FSP experienced a 20 percent drop in household income sometime during the four months before they started receiving food stamps. Similarly, about two third of those who stop receiving food stamps experienced a 20 percent increase in income around the time they left the program. Furthermore, the study indicated that, about one third of the entrants had faced both a decrease in household income and some change in the composition of their households (such as departure of a spouse) during the eight months before they started receiving food stamp.

Household's structure such as marital status, race and level of education can influence FSP participation. Rank and Hirschl (2003) investigated the implication of household's structure on FSP participation. The study noted that race, level of education, and marital status has a substantial influence on the probability that the individual would use food stamps. The study also reported that African Americans, people who have not graduated from high school and children residing in non married households have a higher probability of using food stamp over the course of their lives. For example, 90 
percent of African Americans used food stamps at some point during their childhood compared with 37 percent of white children.

FSP participation span might differ with regard to household structures. Singlefemales with children, elderly people with disabilities, and low income households whose members have not worked recently participate in FSP longer than the others. Furthermore, the increase in the unemployment rate and falling wages in the manufacturing industry leads to longer stays in the program for able bodied participants without children (Gleason et al., 1998).

Previous studies employing static models found that the FSP participation rate is high among non-elderly and those who participate in other public assistance programs. Everything else held constant, those households receiving AFDC, living in poverty, and no longer receiving food stamps, are much more likely to re-enter the program than their counterparts. In addition, individuals in households with children (especially single parents with children) are more likely to enter the program than those in households without children (Gleason et al., 1998).

Based on the 1997 National Survey of America's Families (NSAF), Zedlewski and Brauner (1999) reported that families receiving FS who had been on welfare left FSP at significantly higher rate than their non-welfare counterparts even if they appear to be eligible at all levels of income. The findings of the survey also showed that 62 percent of the former welfare recipient families left the FSP compared to 46 percent of non-welfare recipients. However, significantly more welfare families that left the program fell into the lowest income group - below 50 percent of poverty level - than the non-welfare receivers. In fact, the rate of FSP participation of former welfare recipient families that were 
eligible for benefit was very low even at very low income levels. For instance, in 1997 only 4 out of 10 families were participating (Zedlewski and Brauner, 1999).

The study also identified the most common reason families gave for leaving the FSP. The major reason given by the respondents was increase in earning or finding a new job, including those with extremely low income. However, whether the families left the program based on their assumption of not being qualified for the program or they preferred to stop the program after they began working was unclear.

The second most common reason given by the respondents for leaving the FSP was administrative problems. The poorest families in both the welfare and non-welfare groups were considerably more likely to leave the program due to administrative problems than relatively higher income families. The study also indicated that families that are not on welfare are more likely to give administrative reasons for leaving the program, which suggests that families without cash assistance are more likely to struggle to maintain the program requirement for eligibility. However, why former welfare families left the FSP more often than non-welfare families at similar income level is unknown (Zedlewski and Brauner, 1999).

\subsection{TRENDS IN FOOD STAMP CASELOADS (1994-2000)}

The monthly rate of participation in the FSP has fluctuated greatly over time due to changes in eligibility requirements, fluctuations in economic activity and improvements in the accessibility of program benefits, changes in other federal programs such as Medicaid, changes in federal immigration policy, and changes in the behavior of households. These various factors resulted in a rising caseloads during the late 1970s and 
early 1980s, a declining caseload during the middle and late 1980s, a rising caseload during the early 1990s, and substantial declining after mid 1990s until 1999.

The unprecedented decline in FSP participation during 1994-1999 attracts a great deal of attention from both policy makers and researchers. Several studies such as Ziliak et al. (1997); Blank (1997); Wilde et al. (2000); Grogger (2001); Martini and Wiseman (1997); Figlio et al. (2000); Jacobson et al. (2001); and Danziger (1999) documented that economic conditions were a significant factor in explaining the drop in FS caseloads during this period. Similarly, policy changes, such as the enactment of the Personal Responsibility Act of 1996, had also played a role to the decline in the food stamp caseload. The most direct impact of this policy change was the disqualification of the eligibility of some of legal immigrants and adults between ages 18-50 without-children.

Gleason et al. (2000), using a multivariate model, investigated FSP participation caseloads for the same period of time and showed that 40 percent of the decline is explained by economic factors such as employment and unemployment rate, 2 percent by work requirement, 23 percent by TANF and the remaining is explained by other factors. Employing micro-simulation methodology, Jacobson and Puffer (2000) simulated the impact of economic change and pointed out that of the predicted 11.5 percent reduction in participation, 35.5 percent was explained by policy change under the welfare reform and 64.5 to change in unemployment rate. Wallace and Blank (1999) using both static annual and dynamic monthly food stamp caseload models based on state level panel data, found that food stamp caseloads strongly countercyclical with the state of macroeconomy and that the reform of AFDC led to weak decline in total caseload. Specifically, 
economic condition such as employment and unemployment was responsible for 44 percent of the decline and about 6 percent of the decline impacted by welfare reform.

Wilde (2001) reported that detailed welfare policy change had little effect which ranged from 0 to 2 percent, while 23 percent of the decline was associated with the implementation of the 1996 welfare reform. Likewise, Ziliak et al. (2000) estimated the impact of welfare reform and business cycle on food stamp caseload decline by employing dynamic model as a function of phase caseload, economic factors, AFDC and FS policies, political factors, AFDC caseload level, and unobserved fixed and trending heterogeneity. The results suggested that the robust economy substantially influenced the decline of FS caseload but the estimated aggregate effect of welfare reform was modest. Wilde et al. (2000) using state level data from 1994 to 1998 found that 35, 23 and 12 percent of participation decline resulted from change in economic conditions, program reform, and political variables, respectively. Similarly, using household level data it was found that 28 percent of the change in the participation rate was associated with the decrease in the number of people with annual income below 130 percent of poverty line. Another 55 percent of the total change was due to a decline in the proportion of low income people who participated in FSP and the result was due to economic or policy change or both.

FS benefits are now paid through an EBT card by deducting the purchased amount from the recipients' monthly benefit. The use of EBT card protects the individual from revealing him/her self as a food stamp user to others in a way that the coupon does (Banks, 2003). The Ponza et al. (1999) survey found that non-participant eligible individuals were more likely to participate in FSP benefits if the benefits were provided 
through EBT cards than coupons. However, with low checking account holding among low income households, the ATM type technology underlying the EBT may be a hindrance to some households (Hurst et al. 1998). Ziliak et al. (2000) indicated that states implementing EBT program experienced about 5.5 percent decline in their per capita food stamp caseloads, suggesting that the stigma reducing effect that should increase caseload in the presence of the EBT is dominated by technological barriers that prevent its use.

\subsection{FOOD STAMP PARTICIPATION AND FOOD INSUFFICIENCY}

Despite the wealth of the nation and abundant food supply, and relatively low food prices, many households are food insecure or do not have assured access to enough food to meet their dietary needs for active and healthy lives. Food insecurity has been a significant public health concern. Lack of a healthy diet can affect people's quality of life and result in poor health outcomes.

Food insecurity has been closely related to health problems including increased risk in the development of chronic diseases. Frazao (1996); and Pena and Bacallao (2002) showed that physically inactive adults with poor diets faced a high probability of heart diseases, cancer, strokes, high blood pressure, and diabetes. The impairment of psychological and cognitive function and obesity are the major health problems resulted from poor diet among children.

For the last decades, evidence indicated that hunger and food insecurity have become a serious issue in the nation. Based on Census Bureau survey, Nord et al. (2003) reported that food insecurity and hunger increased in USA in 2002 for the third 
consecutive year. Food insecurity increased by 3.9 million people between 1999 and 2002. Of the increased food insecure people, 2.8 million were adults and more than one million were children. In 2002, 11.1 percent of US households (around 35 million people from 12.1 million households) experienced food insecurity compared to 33 and 31 million people in 2001 and 1999, respectively. About one-third of food-insecure households (3.8 million, or 3.5 percent of all U.S. households) were food insecure to the extent that one or more household members were hungry, at least some time during the year, because they could not afford to have enough food (Nord et al.,2003).

There have been many initiatives by policy makers in identifying effective policies that can reduce food insecurity and address the food needs of vulnerable groups. To address this problem, 15 domestic food assistance programs administered by USDA have become the major safety net for children and low income adults in which food stamp has been the largest one.

With some exceptions (asset and financial requirements) food stamps are available for all low income households and generally it is expected that low income families would be the beneficiaries of the program. However, Jensen (2002) indicated that not all households that experienced food insecurity participated in the food stamp program in the same year. For example, only 42 percent of the households that experienced hunger participated in FSP during the past year. This evidence indicates that many eligible households do not participate in the program and also many of the eligible non-participants may experience food insecurity. Multivariate analysis indicated that the degree of food insecurity is positively correlated with the likelihood of FSP participation, 
and that the labor market and program parameters have a relatively larger effect on more food insecure households than on others.

The contribution of food stamps to reducing food insecurity has been studied by some researchers. Increase in food stamp benefit increased FSP participation and decreased the food insecurity with hunger according to Huffman and Jensen (2003). Their findings implied that FSP participation and food insecurity with hunger among low income and low asset households that are potentially eligible for FSP are sensitive to changes in program parameters (e.g., food stamp benefit). Further, their results suggested that greater reduction in food insecurity can be achieved through increase in FS benefit and improvement of macroeconomic conditions,

In contrast food insecurity was worse among food stamp recipients than among eligible non-participants and near-eligible individuals (Cohen et al., 1999). Their estimate unveiled that half of all the food stamp recipients experienced some kind of food insecurity. Similarly, by employing simultaneous equations, Gunderson and Oliveira (2001) indicated that food insufficient families are more likely to receive food stamps and FSP participants are much more than twice as likely to be food insufficient than non participants while treating the program participation as exogenous variable.

Huffman and Jensen (2003) examined the relationship among FSP participation, labor participation, and food insecurity by employing a simultaneous equation model. They found that if the head of the family is male or married, then the probability that household participants in FSP is significantly lower and the probability that the household head works is significantly higher. They found lower FSP participation for married families, a negative relationship between food participation and labor supply and 
negative relationship between food insecurity with hunger and labor force participation. Likewise, an additional hour of working leads to decreased FSP participation and increased food security. The marginal effects of one dollar increase in expected FS benefits on FSP participation is similar to a one dollar increase in minimum food spending needs: both increase FSP participation by approximately 0.10 percent points, (Jensen, 2002).

Cross sectional studies have generated a variety of conflicting results. For instance, Rose et al. (1998) estimated the effects of different economic and demographic variables on food insufficiency using national sample data. They noted that food insufficiency fell with rising income, food stamp benefit, education, and with home ownership. They also found that household structure, race, and ethnicity are important factors in explaining food insufficiency.

Similarly, single female headed households were 4 percent more likely to participate in the FSP and 5 percent more likely to be food insecure than others (Hanson and Golan, 2002). Winship and Jencks (2002) indicated that single mothers had higher rate of food insufficiency problem than married mothers, but both groups experienced a similar decline in problems over the late 1990s. Likewise, female-headed households were significantly more likely to be food insufficient than other households. In addition, disability status and changes in household's composition appear to be associated with entry in food insufficiency. On the other hand, completing high school was consistently found to increase the chance of being food secure (Nord et al., 2003). 


\subsection{FOOD STAMP EXPENDITURE AND THE ECONOMY}

Considerable research has revealed that FSP participation is responsive to changes in economic conditions. During economic downturn, participation rates tend to increase as unemployment rate increased and income is reduced. On the other hand, during economic expansion FSP participation tends to decrease as the employment rate and income rises. Hanson and Gundersen (2002) stated that general economic conditions influence the number of people to participate in FSP in ways that as households income increase, either fewer households are eligible or the level of benefit for eligible households decline. They also pointed out that the general state of the economy influences the expectation of the individual about their prospects regarding employment and income and, therefore, influences their decision to participate in the program.

Using CPS and FSP administrative data, Cunnyngham (2004) reported that FSP participation is substantially higher for individuals in the household without income than for individuals in the household with income. For example, in 2002, 67 percent of members in the household without income participated as compared to 50 percent of individuals in the household with income. Similar to this result, Ponza et al. (1999), using National Food Stamp Program Survey (NFSPS) collected between 1996 and 1997, stated that food stamp participants are more likely to have no earned income than eligible non participants. They reported that 52.7 percent of FSP eligible non-participant households have earned income as compared to 32.5 percent of participants. They also indicated that there is a negative relationship among FSP participation, number of jobs held, and number of hours worked by adult household member. 
The opposite is also true; an economic downturn increases FSP participation since it creates low work opportunities, fewer hours of available work, and a higher unemployment rate (Hanson and Gundersen, 2002). Lower income implies that new households become eligible to participate in FSP and also families already participating in the program receive more benefits. However, they also indicated that the economy has less direct effect on the household participation whose members have limited attachment on labor force such as the disabled, elderly, and single women with young children.

Hanson and Golan (2002) were also investigated the impact of food stamp spending on stabilizing the economy. These countercyclical changes in food stamp expenditure during economic boom and downturn can have beneficial stabilization effect to the economy, stimulating economic activity during recession and slowing demand during an expansion. The effect of FSP expenditure on the economy during economic downturn can be evaluated in terms of source of expenditure finance: expenditure generated through emergency or contingency funding, and funds generated through increased tax or other budget neutral financing.

At the time of recession, FSP expenditures increase through government emergency finance to provide more benefits to more households. The increase in spending by the benefit recipients due to the rise in FS expenditure stimulates production. The resulting higher production boosts labor market demand and household income and consequently the increase in income triggers additional spending. To understand the likely impact of additional expenditure in FS benefit, Hanson and Golan (2002) investigated the effect of recession-driven increase in FSP spending through emergency borrowing by hypothetically increasing the annual FSP expenditure by $\$ 5$ billion (lower 
than the actual spending increase). According to their estimate, the $\$ 5$ billion rise in the FSP expenditure resulted in $\$ 1.3$ billion increase in food items spending by the recipients of the households. By assuming that the households now allocate their previous income devoted on food to non-food items, they found that non-food spending increased by $\$ 3.7$ billion. Ultimately, the additional $\$ 5$ billion expenditure triggered economic activity of $\$ 9.2$ billion and increase in jobs of 82,100 , out of which 8,800 jobs accounted for farm and food processing sector and 73,300 for nonfood sectors. Likewise, Hanson et. al. (2002) showed the role of FSP expenditure on farm and food processing sector by converting the FSP to cash assistance program. It was indicated that converting $\$ 18.5$ billion FSP to cash assistance would lead to a reduction in farm and food processing production of $\$ 3.5$ billion, as households shifted expenditures from food to other goods and services.

Hanson et al. (2002) also examined the possible implication of food stamp expenditure on the economy, especially on farm and food processing sector, if the program is financed thorough tax increment. They hypothetically increased both FSP benefits and personal income taxes by $\$ 5$ billion. The increase in benefit due to rise in FSP expenditure resulted in rise in spending by recipient households in food and nonfood items. However, the rise in spending of the recipient households was offset by a decline in spending by tax paying households. As a result of increase in benefit expenditure through budgetary neutral spending by low-income households there was an increase by $\$ 1.357$ and 3.608 billion on food goods and nonfood goods and services, respectively. Mid and high income households cut spending by $\$ 159$ million and non food spending by $\$ 5.491$ billion. Even though production increased in farm and food processing sector and 
job increased by 7,870 due to the redistribution of the expenditure, total economy declined by almost $\$ 1$ billion with a loss of 14,000 jobs. The non-farm and non-food processing sector of the economy declined, losing 22,270 jobs. Similarly, they investigated the effect of increase in personal income tax to finance FSP expenditure. It was estimated that increasing personal income taxes by $\$ 1$ billion to offset the additional FSP expenditure resulted in an overall loss of 3,000 jobs and farm sales rise by $\$ 81$ million and with 880 jobs added. 


\section{CHAPTER 3}

\section{THEORETICAL BASIS FOR FOOD STAMP PARTICIPATION DECISIONS}

\subsection{FOOD STAMP PROGRAM PARTICIPATION DECISION}

Despite the potential value of food stamps, many eligible households do not participate in the program, and participation rates have dropped significantly in recent years. For example, it is estimated that 54 percent of eligible households participated in food stamps program during 1999-2001, which was lower than in 1994 with 70 percent participation rate (Zedlewski and Rader, 2004).

Literature provides two general explanations regarding non-participation for the eligible households in the FSP. The first reason focuses on the unawareness or lack of information about the program and its potential benefit by low income families (McConnell and Ponza, 1999). If the households or individuals are unaware of the eligibility, they do not apply for public assistance program regardless of their expected benefit level or the relative direct and psychological costs of participation (Banks, 2003). Some needy households do not participate because they do not know about the program, or more likely, believe that they are not eligible for the benefit.

Previous studies, for example, Coe (1986), agreed that lack of information played an important role for the low level FSP participation of eligible households. Using information from the Panel Study of Income Dynamics, Coe (1986) indicated that 50 percent of non-participating eligible households reported that lack of information was their primary reason for not participating in the program. Blaylock and Smallwood (1984) using 1979-80 survey of Food Consumption in low income households, indicated that lack of knowledge about the FSP, eligibility levels and application procedure were 
the most mentioned reasons for non-participation. Kim and Mergoupis (1997) similarly reported that lack of information contributed for non-participating in FSP. Ponza et al. (1999) suggested that even prior exposure to public assistance program might not provide adequate information regarding the eligibility of the program. The authors found that almost three fourths of non-participating eligible households reported that they were unaware of their eligibility. Most households with prior participation in food stamp program also reported that they were unaware of their eligibility.

Other researchers (Ranney and Kushman, 1987) indicated that households have sufficient information regarding the availability and benefit of the FSP but they decide whether to participate in the program or not after weighing the expected costs and benefits associated with FSP participation. If the expected benefit is higher than the expected cost, households will participate in the program, and vise versa. Non participation can be explained either by low expected benefit level or high expected cost of participation, or both. When the expected benefits are lower than the expected cost of participation, eligible households choose not to participate even though they may be entitled to modest assistance (Ranney and Kushman, 1987). Similarly, a recent study by Lerman and Wiseman (2002) suggested that costs and benefits of participation played an important role in making participation decision. Individuals participate in FSP if the utility of participation in the program is higher than the utility of non-participation.

\subsection{COST AND BENEFIT OF FOOD STAMP PROGRAM PARTICIPATION}

Participation in FSP involves both benefits and costs to the eligible household. The primary benefit of FSP participation is that it provides households resources to purchase 
nutritional food and improve their health. Once the household is eligible, the amount of FS benefit received is determined based on several factors such as: earned income, unearned income, allowable income deductions, household compositions, and year. The amount of benefit is higher for households with lower earned and unearned income as well as for households with higher income deductions such as shelter and medical expense.

The compositions of households also determine the amount of benefit, as the amount of food stamp benefit increases with the number of persons in the household. FSP participation rates declined sharply with income relative to need and this income relative to need is a function of both household income and household size (Zedlewski and Brauner, 1999). The time period of food stamp receipt is also related to the benefit of participation as there have been changes both in policies and the amount of benefit of participation over time.

Non-market costs (transaction and stigma) are involved in FSP participation decision. Transaction costs of participation include, but not limited to, out of pocket cost of transportation to public assistance offices, incremental costs of documenting additional family members, the time costs of going to the food stamp office and waiting in public assistance offices, and time spent to gather information and documentation for the program application. Ponza et al. (1999) indicated that individuals spend roughly an average of five hours applying for food stamps and two and half hours to recertify benefits.

Loss of earning is also one of the costs the participant household faces since some workers may have to miss work in order to recertify for benefit during office hours. This 
increases the opportunity cost of participation especially for those who work during traditional working hours as the food stamp office is open during the same hours. Due to the time taken for the intensive application and recertification process, the cost of participation for these eligible groups of people is very high (McKernan and Ratcliffe, 2003). Examining the relationship between FSP participation and detailed employment characteristics using data from 1990 and 1996 panel of Survey of Income and Program Participation (SIPP), McKernan and Ratcliffe (2003) found that individuals in households where adults work traditional daytime hours are less likely to participate in FSP than individuals in the households where adults work in non-traditional hours. This implies that working in traditional day time hours makes it difficult for the individuals to go to office to apply and certify for the FSP.

Participation in the program also causes a stigma ${ }^{4}$ cost or disutility to the household. Stigma cost may be incurred during the application and certification process (Ranney and Kushman, 1987). The applicant may feel stigmatized by being seen going into the food stamp office, being identified as a poor by others, or having to reveal personal information to workers. Stigma cost may also occur as the person uses the coupon card every time store purchases are made.

\subsection{THEORETICAL MODEL OF FOOD STAMP PROGRAM PARTICIPATION}

One of the basic assumptions in microeconomic theory is that rational individuals choose bundles of goods and services that maximize their utility based on, among other things,

\footnotetext{
4 According to Weisbrod (1970, pp 2-3) stigma is describes as “... the desire of the "poor" or "needy" to retain self respect, dignity and acceptance from the rest of the society, and in particular the desire not have other people know about poverty,...(or) private life."
} 
income, preference, and relative prices. For FSP eligible households, utility maximization depends on income, preference, relative prices, program participation decisions, both benefits and costs associated with program participation and characteristics of the households. To maximize utility, the eligible household must first make the FSP participation decision and then determine the level of food demand (out of their income) and other non-food goods and services as part of income allocation process. Eligible households may make the rational choice not to participate in the program by forgoing additional resources from food stamps if the cost of participation in FSP is higher than its benefit. The following theoretical model of FSP participation decision is developed following Ranney and Kushman (1987).

The utility function can be represented as:

$$
U=U\left(H, F_{Y}+F_{S}, R, M\right)
$$

where $F_{Y}+F_{S}=F_{T}$ and $R=R\left(F_{S}, M\right) ; H$ is a Hicksian composite of all non-food goods and services, $F_{Y}$ is food bought with cash, $F_{S}$ is food purchased with stamps, $F_{T}$ represents total food consumption from cash and food stamps, $R$ is a composite representing the household's status or prestige and $M$ represents the household's characteristics such as age, sex, educational attainment, status of the head of the household and other demographic characteristics.

Throughout the discussion of this model, non-satiation (higher quantities provide greater level of satisfaction) and one decision maker per household are assumed. The household has $Y$ level of income (income after taxes), which might consist of non-welfare earned income and cash welfare income (if any). It is assumed that the household has information regarding the FSP and they are eligible to participate in the program. 
The utility maximizing problem for FSP eligible household can be represented

as:

$$
\begin{aligned}
& \operatorname{Max} U=U\left(H, F_{Y}+F_{S}, M, R\right) \\
& \text { s.t } \quad P_{F} F_{Y}+P_{H} H \leq Y^{\prime} \quad \text { where } Y^{\prime}=Y-C \\
& P_{F} F_{S} \leq A \\
& R=R\left(F_{S}, M\right) \\
& H>0, F_{Y} \geq 0, F_{S} \geq 0 \text { and } F_{Y}+F_{S}>0
\end{aligned}
$$

where $P_{F}$ is price of food, $P_{H}$ is price of the Hicksian good, $Y$ is income, $C$ is the transaction cost of participating in FSP, $Y^{\prime}$ is transaction cost adjusted income, and $A$ is total allotted amount of benefit. $H>0$ indicates that non food items will be consumed whether or not food stamps are used by the household. $F_{Y} \geq 0$ shows that food items may or may not be purchased using cash or income. Similarly, $F_{S} \geq 0$ indicates that households may not use food stamps and $F_{Y}+F_{S}>0$ shows that households consume food items by spending either their income and/or using food stamps.

The utility maximizing household is constrained by the level of income (equation 3.3) after accounting for the transaction cost of participation. The amount of food stamps allocated to the household is also constrained by the allotted amount of benefit available for that household as indicated in equation 3.4. Equation 3.5 shows the prestige or status of the household determined by the household characteristics, FSP decisions and usage of food stamps.

The Langrangian equation of the constrained utility maximization problem can be expressed as: 


$$
L=U\left(H, F_{Y}+F_{S}, R, M\right)+\lambda_{1}\left(Y^{\prime}-P_{F} F_{Y}-P_{H} H\right)+\lambda_{2}\left(A-P_{F} F_{S}\right) .
$$

Since the constraints are expressed in terms of inequality expression, KuhnTucker conditions are used for setting the first order conditions. The Kuhn-Tucker conditions to maximize $U$ can be specified as:

$$
\begin{aligned}
& \frac{\partial L}{\partial F_{Y}}=\frac{\partial U}{\partial F_{Y}}-\lambda_{1} P_{F} \leq 0 \\
& F_{Y} \frac{\partial L}{\partial F_{Y}}=0
\end{aligned}
$$

$\frac{\partial L}{\partial F_{S}}=\frac{\partial U}{\partial F_{S}}+\frac{\partial U}{\partial R} \frac{\partial R}{\partial F_{S}}-\lambda_{2} P_{F} \leq 0$

$F_{S} \frac{\partial L}{\partial F_{S}}=0$

$\frac{\partial L}{\partial H}=\frac{\partial U}{\partial H}-\lambda_{1} P_{H} \leq 0$

$H \frac{\partial L}{\partial H}=0$

$\frac{\partial L}{\partial \lambda_{1}}=Y^{\prime}-P_{F}-P_{H} H \geq 0$

$\lambda_{1} \frac{\partial L}{\partial \lambda_{1}}=0$

$\frac{\partial L}{\partial \lambda_{2}}=A-P_{F} F_{S} \geq 0$

$$
\lambda_{2} \frac{\partial L}{\partial \lambda_{2}}=0
$$

$$
F_{Y} \geq 0, H>0 \text { and } F_{S} \geq 0
$$


Based on the first order and Kuhn-Tucker conditions, three cases are considered to examine the utility maximizing conditions for the participant household.

Case 1: $F_{S}=0$ (no food stamp benefits used): In this case, eligible households undertake the necessary procedure and certification. However, households prefer to purchase food with cash by allocating some portion of their income instead of food stamps. Since the utility maximization model considers net income after accounting for transaction cost associated with FSP participation, the decision of not participating in the FSP implies that the variable cost of the stigma is higher than the benefit of the stamp for these households.

From equation $3.15 \quad \frac{\partial L}{\partial \lambda_{2}}=A-P_{F}(0) \geq 0 \quad, \quad A>0$

Therefore, from equation $3.16 \lambda_{2} \frac{\partial L}{\partial \lambda_{2}}=0$, and, $\lambda_{2}=0$ since $\frac{\partial L}{\partial \lambda_{2}}>0$.

In this case, $\lambda_{2}=0$, which indicates that a marginal increase in food stamp allotment does not increase the household's utility since the household does not use the food stamps to purchase food.

The behavior of the household can also be expressed graphically in terms of indifference curves. Figure 3.1 shows the indifference curve of a household that does not participate in FSP despite benefit is allocated to the household. 
Figure 3.1. Indifference Curve of a Household not Using Food Stamps Despite being Eligible for Participation.

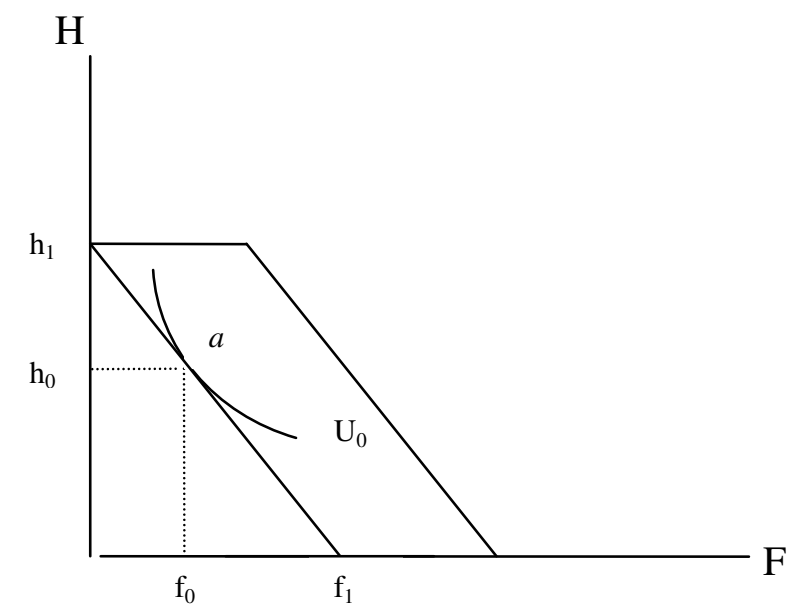

The household consumes $\mathrm{f}_{0}$ and $\mathrm{h}_{0}$ level of food and Hicksian goods, respectively before and after participating in the program. The equilibrium point that maximizes utility is point $a$ in both cases (before and after participating in the program). Even if the budget line of the household shifts by the amount of the food stamp benefit, the household retains the same utility level since the household does not use it.

Case 2: $0<F_{S}<\frac{A}{P_{F}}$ : In this case the household uses the food stamps but does not exhaust the entire amount. Given this condition, the optimal condition can be characterized as:

From equation $3.15 \frac{\partial L}{\partial \lambda_{2}}=A-P_{F} F_{S} \geq 0 \Rightarrow A>0$ since $F_{S}<\frac{A}{P_{F}}$ thus $\frac{\partial L}{\partial \lambda_{2}}>0$.

From equation $3.10 \frac{\partial L}{\partial F_{S}}=0 \quad F_{S}>0$ since some food is bought using food stamps.

Therefore, from equation $3.16 \lambda_{2} \frac{\partial L}{\partial \lambda_{2}}=0$, and, $\lambda_{2}=0$ since $\frac{\partial L}{\partial \lambda_{2}}>0$. 
Consider equation $3.9 \frac{\partial L}{\partial F_{S}}=\frac{\partial U}{\partial F_{S}}+\frac{\partial U}{\partial R} \frac{\partial R}{\partial F_{S}}-\lambda_{2} P_{F}=0$, then, following the above arguments, $\frac{\partial U}{\partial F_{S}}=-\frac{\partial U}{\partial R} \frac{\partial R}{\partial F_{S}}$.

Since the household does not exhaust the entire food stamp allocation, $A$ in equation (3.15) is not binding, indicating that the household's food consumption is not constrained by the amount of food stamp allotment. Equation 3.18 indicates that the households purchase food with food stamps until the marginal utility of food purchased with food stamps is equal to the marginal disutility of the stigma associated with using the food stamps. The marginal increase in total benefit does not increase the utility of the household since the household does not use the entire food stamp benefit, the additional benefit from using food stamps might not have an effect on the utility of the household's food consumption i.e $\lambda_{2}=0$. Figure 3.2 shows the indifference curve of a household that does not use the entire benefit.

Figure 3.2. Indifference Curve of a Household that Does Not Exhaust the Entire Food Stamp Benefit

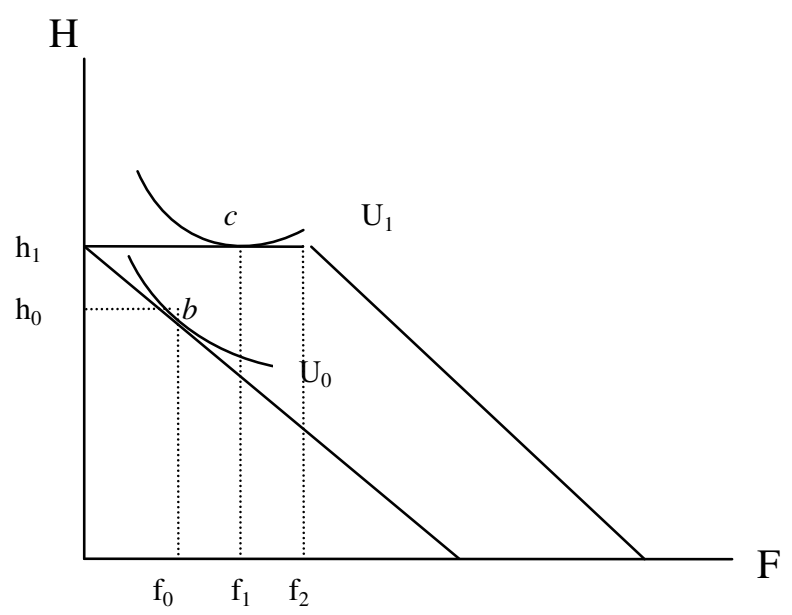


Originally the household allocates its income among Hicksian goods and food items at equilibrium point of $b$ by consuming $f_{0}$ and $h_{0}$ amount of food and Hicksian goods, respectively. After participating in the program the household only uses part of the allotted food stamps and spends the entire income on Hicksian goods. The new equilibrium point that maximizes utility is point $c$ where the household consumes $f_{l}$ and $h_{1}$ amount of food and Hicksian goods, respectively.

Case 3.: $F_{S}=\frac{A}{P_{F}}$ In this case the household exhausts the benefit of food stamps. Two different scenarios are considered in this situation. Where $\lambda_{2}=0$, which indicates that the household exhausts the entire food stamp benefit and even if the food stamp allotment increases the household does not use it, and $\lambda_{2}>0$ indicates that the household uses the entire benefit and if additional food stamp is allocated, the household will use it.

For the case where $\lambda_{2}=0, F_{Y}>0$ and $F_{Y}=0$, the household fully utilizes the allotted benefit and additional food may or may not be purchased using cash. Under this scenario, equilibrium occurs (for both $F_{Y}>0$ and $F_{Y}=0$ ) at the point where the marginal utility of food purchase with food stamps equals to the marginal disutility of food stamps:

$$
\frac{\partial U}{\partial F_{S}}=-\frac{\partial U}{\partial R} \frac{\partial R}{\partial F_{S}} .
$$

For the case $\lambda_{2}>0, F_{Y}>0$ and $F_{Y}=0$, the marginal increase in benefit increases the household utility. Again the household may or may not purchase food with cash.

From equation 3.10, since $F_{S} \frac{\partial L}{\partial F_{S}}=0$ and $F_{S}>0$ thus, $\frac{\partial L}{\partial F_{S}}=0$. 
From equation 3.9, $\frac{\partial U}{\partial F_{S}}+\frac{\partial U}{\partial R} \frac{\partial R}{\partial F_{S}}=\lambda_{2} P_{F}$, and $\frac{\partial U}{\partial F_{S}}+\frac{\partial U}{\partial R} \frac{\partial R}{\partial F_{S}}>0$ since $\lambda_{2}>0$ and $P_{F}>0$.

Therefore, after rearranging the above equation $\frac{\partial U}{\partial F_{S}}>-\left(\frac{\partial U}{\partial R} \frac{\partial R}{\partial F_{S}}\right)$.

Equation 3.19 implies that at equilibrium, the marginal utility from food stamps is greater than the marginal disutility associated with participation.

$$
\text { If } F_{Y}=0 \text { and } F_{S}=\frac{A}{P_{F}} \text {, from equation (3.14) } Y^{\prime}=P_{H} H \text { which indicates that the }
$$

entire income is allocated for non food items of other goods and services. This behavior of the household under this scenario is presented graphically in terms of indifference curves in figure 3.3.

Figure 3.3 Indifference Curve of a Household that Exhausts the Food Stamp Benefit but Does Not Spend Income to Purchase Additional Food

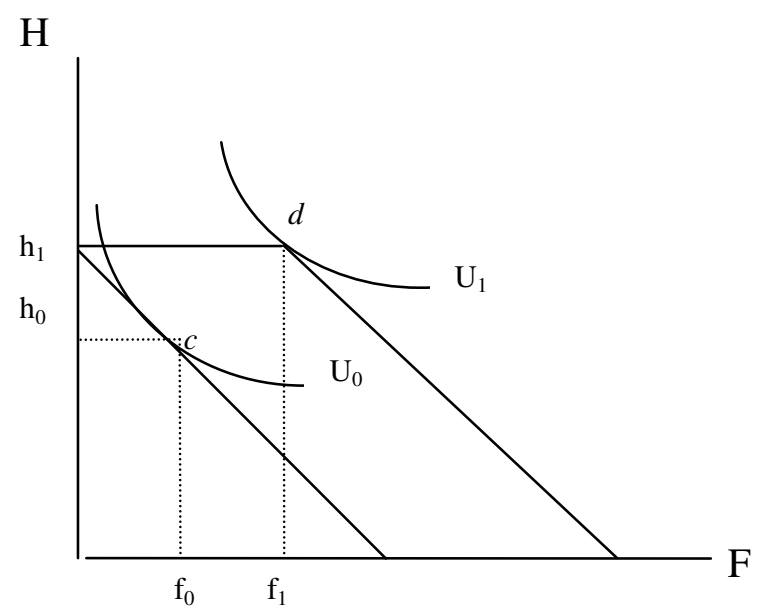

Before participating in FSP program, the household used to consume $f_{0}$ level of food and $\mathrm{h}_{0}$ level of Hicksian goods. Consumption of food and Hicksian goods increases after participating in the FSP. The household now consumes $f_{l}$ and $h_{l}$ level of food and 
Hicksian goods, respectively. The new utility maximizing level of consumption is achieved at point $d$.

If $F_{Y}>0$ and $F_{S}=\frac{A}{P_{F}}$ which indicates that the household allocates income to food and Hicksian goods.

From equations 3.7 and $3.8, \frac{\partial U}{\partial F_{Y}}=\lambda_{1} P_{F}$.

If $H>0$ and $F_{S}=\frac{A}{P_{F}}$, then

from equations 3.11 and $3.12, \frac{\partial U}{\partial H}=\lambda_{1} P_{H}$

and, from equations 3.20 and $3.21 \frac{\partial U / \partial F_{Y}}{\partial U / \partial H}=\frac{P_{F}}{P_{H}}$.

Equation 3.22 indicates that at equilibrium point the marginal rate of substitution between food and other goods and services is equal to their price ratio. Given household participation, the Marshallian demand for food out of income is represented as: $F_{Y}=F\left(P_{F}, P_{H}, Y^{\prime}, A, M\right)$. Therefore, for eligible households, food demand out of cash is determined by the price of food, the price of other goods and services, income (after accounting to the transaction cost), amount of food stamp benefit, and characteristics of the household.

Figure 3.4 depicts the indifference curve of a household that allocates income for both food and Hicksian good purchases. 
Figure 3.4. Indifference Curve of a Household that Allocates Income to Purchase Additional Food

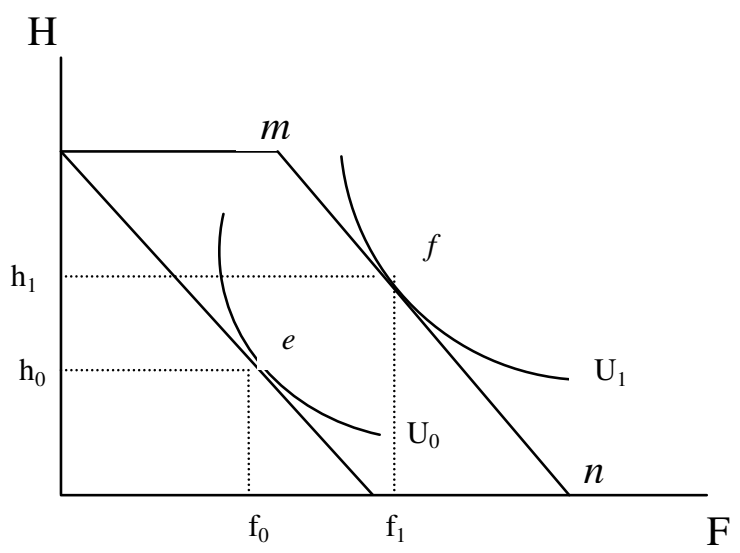

Before participating in FSP, the household maximizes utility by consuming $\mathrm{f}_{0}$ and

$\mathrm{h}_{0}$ level of food and Hicksian goods, respectively at equilibrium point of $e$. Now the household consumes the combination of food and Hicksian goods by allocating income for the two goods and participating in FSP. The amount of income allocated for both goods depends on the household's preference of what to consume more. If the household prefers to consume more of food, it will allocate a higher proportion of income to food and the equilibrium point where utility is maximized would be closer to $n$. Similarly, if the household prefers to spend less on food and more on Hicksian goods, the utility maximizing equilibrium point will be close to point $m$. It is also possible that the household allocates income equally to both food and Hicksian goods. 


\section{CHAPTER 4}

\section{EMPIRICAL MODELING OF FOOD STAMP PARTICIPATION}

\subsection{MODEL SPECIFICATION}

Participation in FSP is an individual's or household's voluntary decision to receive monthly benefit by fulfilling all the eligibility requirements. The theoretical model developed in chapter three explained that participation decisions by households depends on the household economic situation, such as income, the price of goods and services, stigma, food stamp benefit level, and composition of the household.

Similar to other economic decision making, household participation in FSP involves a set of benefit and cost considerations. Chapter three discussed the microeconomic foundation behind FSP participation decisions. Households are interested in maximizing their utility from the consumption of goods and services and from participation in FSP that generates a flow of benefits.

Income, household composition, household employment, the cost of food and other goods and services, and other household characteristics are important parameters that affect FSP participation decisions of a household. Although the combination of declining income and change in household structure generally lead to FSP participation, income change triggers most movement into and out of the FSP (Gleason et al., 1998). Household characteristics in terms of poverty level, employment status, family structure, for example number of dependants, are also important in determining criteria that can affect the economic decision of participation in FSP. 
Direct observation of these household socio-economic parameters that influence FSP participation decisions requires detailed survey data. This approach provides an understanding of the relationship between household economic conditions and FSP participation decisions using micro-level household modeling method, like logit and probit models. The interest of the present study is rather to abstract from household-level FSP decision modeling to a more general county level macro modeling of FSP decisions that may have relevant bearing on welfare program policies. However, such transition from micro-level modeling to macro-level modeling first requires establishing proper links between micro-level economic parameters and ways to observe them using generalized data.

Household income is an important variable in understanding FSP participation patterns. To account for this household economic variable, county per capita income is used to measure the county level relationship between income and FSP participation. This study assumes that county level per capita income trends reflect the county's level household income.

Another economic factor that might determine household's FSP participation decisions is household employment status. This study uses county level of employment and unemployment growth rate variables as proxies for household employment and unemployment status, respectively. The effectiveness of county level employment and unemployment growth rate as a proxy for household employment depends on how cycles in county employment and unemployment reflect similar patterns at the household level.

Aside from income and employment, the household FSP participation decision is affected by the degree of household poverty. As a direct extrapolation, the county level 
measure of poverty is used as a proxy variable for household poverty levels. It is measured as the percentage of persons in a county that are in poverty.

As a direct proxy for household FSP participation, the percentage of people who participate in the FSP out of the total population in that county is introduced. As a proxy variable, it is more likely that the county level percentage of FSP participation captures household level participation decisions.

To empirically analyze the impact of economic and policy factors on FSP participation, two econometric models are used: static and dynamic models. In the static model, the explanatory variables for period, say, $t=j(j=1, \ldots, n)$ are assumed to affect participation in the same period, $t=j$. In the dynamic model, the dependent variable (FSP) depends on lagged participation in period $t$-j (where $j$ represent the number of lags, and $j=1, \ldots n)$, lagged macroeconomic variables as well as current macroeconomic and policy variables are used. The rationale for using the dynamic model is that an event in one period may affect program participation for several subsequent periods due to lags in the adjustment of economic variables.

Both static and dynamic econometric models of the study are developed following the models and approaches employed by Wallace and Blank (1999), Figlio et al., (2000) and Ziliak et al., (2003). These studies developed both static and dynamic models to examine the impact of economic variables, policy, and political variables on food stamp caseloads using nationwide state panel data. In their empirical estimation, they considered food stamp caseload as the dependent variable and many independent variables such as employment growth rate, unemployment rate, welfare reform indicator, EBT (Electronic Benefits Transfer) indicator, a vector that indicated the political 
environment of each state, able-bodied adult without dependent (ABAWD) wavier, and other variables.

In this empirical study, static and dynamic models are developed to test the relationship between FSP participation and county level economic and policy variables in West Virginia. The empirical models and data collection are discussed in the following sections.

\subsubsection{Static Model}

In the static model, given a general model $Y_{i t}=\beta_{i t} X_{i t}+\varepsilon_{i}$, the effect of the independent variables $X$ at year $t$ on the dependent variable $Y$ at the same period is examined. The presumption of the static model is that prior events that occurred in lagged periods do not significantly affect the present event, or mathematically $\operatorname{cor}\left(Y_{t}, X_{t-1}\right)=0$, where $\operatorname{cor}$ refers to correlation, $Y_{t}$ is the dependent variable at time $t$, and $X_{t-1}$ is all the lagged explanatory variable arguments that can be introduced in the model. A zero correlation in this case means that the dependent variable $Y$ is independent of the influence of lagged explanatory variables.

A number of explanatory variables are introduced for empirical estimation. For empirical estimation, panel data (time series and cross-section) is introduced for all variables. The macroeconomic variables included are county level unemployment rate, employment growth rate, per capita personal income, percentage of county population under poverty, and consumer price index. Personal Responsibility and Work Opportunity Reconciliation Act of 1996 (PROWRA) is also included to capture the policy variable. However, even if EBT is another policy variable it is excluded from the model as this 
policy is introduced in 2002 in West Virginia and no sufficient time is covered by this policy for estimation of its impact on FSP participation.

The static empirical econometric model can be specified as:

$$
F S P_{i t}=f\left(U E M P R_{i t}, E M P G_{i t}, P C P I_{i t}, P O V_{i t}, C P I_{i t}, P R W O R A_{i t}, G O V_{i t}, t\right)
$$

Where $F S P_{i t}=$ percentage of population participating in food stamp program in county $i$ in year $t$

$U E M P R_{i t}=$ unemployment rate in county $i$ in year $t$

$E M P G_{i t}=$ employment growth rate in county $i$ in year $t$

$P C P I_{i t}=$ per capita personal income

$P O V_{i t}=$ percentage of people living in poverty in county $i$ in year $t$.

$C P_{i t}=$ consumer price index at time $t$

$P R W O R A_{\mathrm{t}}=$ Personal Responsibility And Work Opportunity Reconciliation Act of 1996

$G O V_{t}=$ political affiliation of governor in office at time $t$

$$
t=\text { trend variable }
$$

$i$ and $t=$ represents counties and year (time), respectively

The functional relationship in equation (4.1) hypothesizes that food stamp caseloads are a function of employment and income opportunities, welfare reform, proportion of the county population living in poverty, general price level, and a time trend variable.

From equation (1), a static model can be specified as:

$$
F S P_{i t}=\beta_{0}+\beta_{1} U E M P R_{i t}+\beta_{2} E M P G_{i t}+\beta_{3} P C P I_{i t}+\beta_{4} P O V_{i t}+\beta_{5} C P I_{t}+\beta_{6} P R W O R A_{t}+\beta_{7} G O V_{t}+\beta_{8} t+u_{i}
$$


This model is estimated using least-squares-dummy-variable method, which is discussed further in chapter 5.

\subsubsection{Dynamic Model}

Though the static model is important in examining the relationship between socioeconomic variables and FSP participation, the argument that past socio-economic conditions may not affect current FSP levels makes the model restrictive.

Last period economic performance may affect the current FSP participation decision and eligibility. For example, lagged unemployment and employment rates may affect the current FSP participation decision and eligibility. Since most of the food stamp recipients are characterized as low skilled and less educated, therefore, they are less likely to be employed instantaneously as the economy booms (McKernan, 2003). Unemployed people may not also be eligible in the program instantaneously, rather after adjusting down or lowering their initial asset level to the eligibility requirement so that they become eligible in the program (Figlio et al., 2000; Ziliak et al., 2002). Hanson and Gundersen (2002) also explained the effect of lagged unemployment on current FSP participation. For some people who lose their jobs during economic downturn, unemployment insurance benefits offset a portion of the lost earning. As a result, many households or individuals remain ineligible for the program. However, the FSP is particularly important for many workers not covered by unemployment insurance, particularly those in low wage jobs. Conversely, during economic expansion, the FSP participation does not respond instantaneously as new employed persons may not quickly exit FSP until program participation is renewed (Ziliak et al., 2003). 
Unlike static model, the use of dynamic model makes it possible to see the effect of economic changes beyond the current period. The dynamic model assumes that food assistance recipients of this year are more likely to be food stamp recipients next year than those not receiving food stamp this year (Hanson and Gundersen, 2002; Figlio et al., 2000). Lagged FSP is used as control variable for the implication of previous year participation decision on current decision.

A dynamic model also captures the delay of non-recipients to enroll in the program after becoming unemployed. A dynamic model allows the sluggish adjustment of food stamp participation to lagged food stamp participation, unemployment rate, employment rate, per capita income, and cost of living. Hence, the assumption that past socio-economic patterns may not affect current period FSP is relaxed. In a dynamic model, $\operatorname{cor}\left(\mathrm{FSP}_{\mathrm{t}}, \mathrm{X}_{\mathrm{t}-1}\right) \neq 0$. The impact of past socio-economic variables may be equal or different from zero. The statistical significance of these variables being equal to zero or different from zero can be tested after estimation of the dynamic model.

The dynamic model of FSP participation is specified as follows:

$$
F S P_{i t}=f\left(F S P_{i t-j}, U E M P R_{i t-j}, E M P G_{i t-j}, P C P I_{i t-j}, P O V_{i t-j}, C P I_{t-j}, R\right)
$$

where $R=f\left(U E M P R_{i t}, E M P G_{i t}, P C P I_{i t}, P O V_{i t}, C P I_{t}, P R W O R A_{t}, G O V_{t}, t\right)$ and

$$
j=1,2,3 \ldots 6
$$

Since the data covers seven years, the maximum lag that can be introduced is six lag period.

Following equation (4.3), the dynamic estimation model can be specified as:

$$
F S P_{i t}=\beta_{0}+\sum_{j=0}^{J} \beta_{1} U E M P R_{i t-j}+\sum_{j=0}^{J} \beta_{2} E M P G_{i t-j}+\sum_{j=1}^{J} \beta_{3} F S P_{i t-j}+\sum_{j=0}^{J} \beta_{4} P C P I_{i t-j}+\sum_{j=0}^{J} \beta_{5} P O V_{i t-j}+\sum_{j=0}^{J} \beta_{6} C P I_{i t-j}+\sum_{\beta(n=7)}^{n=13} \beta_{n} R_{i t}
$$


where

$$
\sum_{\beta=7)}^{13} \beta_{n} R_{i t}=\beta_{7} U E M P R_{i t}+\beta_{8} E M P G_{i t}+\beta_{9} P C I P_{i t}+\beta_{10} P O V_{i t}+\beta_{11} C P I_{i t}+\beta_{12} P R W O R A_{i t}+\beta_{13} t+u_{i t}
$$

where $F S P_{i t-j}$ denotes lag FSP

$U E M P R_{i t-j}=$ lag unemployment growth rate

$E M P G_{i t-j}=$ lag employment growth rate

$P C P I_{i t-j}=$ lag per-capita Income

$P O V_{i t-j}=$ lag level of Poverty measured in terms of percentage of people who live in poverty

$C P I_{t-j}=$ lag consumer price index

Thus, this dynamic model integrates the static model variables and develops a lagged variable argument for FSP, unemployment rate, employment growth rate, and poverty.

\subsection{METHOD OF ESTIMATION}

Both static and dynamic models use county level panel data. As such, estimation of the two models needs to take into account the econometric methods applied to panel data models. Panel data models provide regression analysis with both spatial and temporal dimensions. The spatial dimension shows a set of cross-sectional units or observations. In this case the spatial dimension represents West Virginia counties. The temporal dimension pertains to periodic observation of a set of variables characterizing the crosssectional units over a particular span of time. 
Panel data can be used to deal with heterogeneity in cross-sectional observations. In any cross-section, there might be many unmeasured explanatory variables that affect the behavior of the cross-sections being analyzed. Cross-sectional heterogeneity may indicate that there could be many unmeasured variables that influence the dependent variable. This phenomenon suggests that pooled OLS is a biased estimator unless the influence of this omitted variation (embodied in different intercepts) is uncorrelated with the included explanatory variables (Wooldridge, 2006).

There are two types of estimation approaches for panel data models: pooled regression method and fixed effects estimation method. The pooled regression method is based on the assumption that all coefficients of the explanatory variables and the intercept considered in the model are constant for all counties across time. This method of estimation assumes homogeneity, i.e., all counties are not different from one another in fundamental unmeasured ways. This restricted assumption might distort the true picture of the result since all counties might not possess similar characteristics that do not change over time (time-invariant). The specifications of pool regression method for static and dynamic model are the same as the specification shown in equations 4.2 and 4.4, respectively.

However, in reality counties may possess different time-invariant characteristics. For example, demographic composition such as race, gender, religion, etc are timeinvariant variables that do not change over time and the distribution might not be the same in each county. As indicated in chapter 2, FSP participation is different among different demographic groups based on marital status of the household, age, and race. Historical data suggested that FSP participation is higher among single parents and 
children but participation is lower among seniors. Similarly, FSP participation is also different among racial groups.

Counties may have different demographic composition. For example, the proportion of single-parent households living in one county might differ from the other county. The same might hold true for other demographic characteristics such as race and age. Differences in demographic composition among counties might lead to differences in FSP. Therefore, in addition to the economic and policy factors, county specific timeinvariant factors might affect FSP. Based on this discussion, county homogeneity assumption of pooled regression method might not be valid.

The fixed effects method of estimation relaxes the county homogeneity assumption by accounting for county differences. The fixed effects estimation method for static and dynamic models is specified in equation (4.5) and equation (4.6), respectively.

$$
\begin{gathered}
F S P_{i t}=\beta_{6}+\beta U E M P R_{i t}+\beta_{2} E M P G_{i t}+\beta_{3} P C P I_{i t}+\beta_{4} P O V_{i t}+\beta_{5} C P I_{i t}+\beta_{6} P R W O R A_{t i}+\beta_{7} E B T_{i t}+\beta_{8} G O V_{t}+\beta_{9} t+a_{i}+u_{i} \text { (4.5) } \\
F S P_{i t}=\beta_{0}+\sum_{j=0}^{J} \beta_{1} U E M P R_{i t-j}+\sum_{j=0}^{J} \beta_{2} E M P G_{i t-j}+\sum_{j=1}^{J} \beta_{3} F S P_{i t-j}+\sum_{j=0}^{J} \beta_{4} P C P I_{i t-j}+\sum_{j=0}^{J} \beta_{5} P O V_{i t-j}+\sum_{j=0}^{J} \beta_{6} C P I_{i t-j} \sum_{\beta(n=7)}^{n=13} \beta_{n} R_{i t} \\
\text { where } \sum_{\beta(n=7)}^{n=13} \beta_{n} R_{i t}=\beta_{7} U E M P R_{i t}+\beta_{8} E M P G_{i t}+\beta_{9} P C I P_{i t}+\beta_{10} P O V_{i t}+\beta_{11} C P I_{i t}+\beta_{12} P R W O R A_{t i}+\beta_{13} t+a_{i}+u_{i t}
\end{gathered}
$$

The fixed effects method of estimation introduces the variable $a_{i}$ for both static and dynamic models. This variable captures all unobserved time-invariant variables that may affect the dependent variable.

Estimation of the variable $a_{i}$ necessitates the introduction of dummy variables for all cross-section observations in the model. Dummy variable of each cross section 
captures the effect of county's time-invariant variables on food stamp participation. The inclusion of dummy variables will eliminate $a_{i}$ and the impact of time-invariant variables reflected on intercept and introduced dummy variables. The approach this study follows to introduce dummy variables in the model is discussed in chapter 5.

Some variables such as EBT, demographic characteristics (such as proportion of single headed households, elderly, disabled) are important variables that might affect food stamp participation decision beside economic and policy variables. The introduction of EBT in the model would expect to control the stigma cost associated with FSP participation. However, the data that this study relies on is limited before EBT became functional in all West Virginia counties, therefore, the model does not control for the effect of EBT on FSP participation. Similarly, due to unavailability of data, demographic characteristics are not included in the model. However, the impact of these variables is accounted by the variable $a_{i}$.

\subsection{TYPES AND SOURCES OF DATA}

The study of FSP participation and the factors that determine the individual or the household participation in the program needs to examine the economic, policy, and demographic factors and their interaction with FSP. The need for identifying factors that influence FS participation necessitates extensive data collection and organization.

In this study, the employment growth rate and unemployment rate of each county is used to examine the impact of economic cycles on FSP. Both employment and unemployment variables are based on time series data included in the model to capture the labor market condition of West Virginia counties. Also, to examine the impact of 
poverty level on FSP, data on percentage of county population who live in poverty is collected.

Policy change is another important variable that is considered in the model. The policy variable is constructed as a discrete dummy variable that corresponds to the enactment and implementation of the policy at a given time period. For the time period prior to the introduction of PROWRA, the dummy variable is assigned a value of 0 and for the time period from 1997 to 2002, it is assigned a value of 1.

The political variable measures the political climate in West Virginia over the period under consideration. States cannot propose major policy changes or directly alter FSP eligibility or payment rules through state legislation or regulation (Wallace and Blank 1999). However, this study incorporates this variable to test whether people's perception of FSP participation differs with political affiliation of governors.

In this study, a dummy variable is introduced to account the political affiliation of West Virginia's governors. The values of dummy variable assigned for democrat governor is 1 and 0 for republican governor. The goal is to test whether food stamp program participation decision is influenced by governor's political affiliation.

For the purpose of empirical estimation, the study uses panel data. Panel data is compose of both cross-section and time series data. The study uses all 55 counties of West Virginia as a cross-section and considered 7 years of observations $(1995,1997-$ 2002).

County level time series data for each variable included in the model is collected from different sources. Table 4.1 presents the variables with their respective data sources. 
Table 4.1.Sources of data.

\begin{tabular}{ll}
\hline \multicolumn{1}{c}{ Types of Data } & Sources of Data \\
\hline Population by county & WVBEP, Census Bureau \\
Employment and Unemployment by county & WVBEP \& BBER \\
Per capital Personal Income by county & WVBEP \\
Poverty by county & US Census Bureau \\
Electronic Benefit Transfer (EBT) by county & WVDDHR \\
FSP by county & WVDDHR \& USDA \\
Consumer Price Index & WVBEP \& BBER \\
PROWRA (Personal Responsibility and Work & WVDDHR \\
Opportunity Reconciliation Act) & \\
Governor & NGA \\
Note: WVBEP = West Virginia Bureau of Employment Program \\
BBER = Bureau of Business and Economic Research \\
WVDDH = West Virginia Department of Health \& Human Service \\
USDA = United States Department of Agriculture \\
NGA = National Governors Association
\end{tabular}




\section{CHAPTER 5}

\section{EMPIRICAL RESULTS AND ANALYSIS}

\subsection{ESTIMATION PROCEDURES}

Determining the appropriate estimation method is very important in finding unbiased results. Two types of panel analytic methods of estimation: pooled regression method and fixed effect method are considered. Pooled method of estimation assumes county homogeneity; however, fixed method of estimation assumes county heterogeneity.

The fixed effect model is estimated using the Least Squares Dummy Variable (LSDV) method. LSDV method of estimation captures the unmeasured time-invariant variables that may explain FSP by specifying dummy variables for each county. The introduction of dummy variables controls for fixed effect variables $a_{i}$ as shown in equation 7 and 8 of chapter 4 . To avoid dummy variable trap (i.e., the situation of perfect collinearity) in the estimation, $n-1$ dummy variables, where $n$ represents number of counties, are introduced.

Aside from the advantage of fixed effect method that recognizes the fact those counties may have their own specific characteristics or unobserved differences, this estimation method has its own drawbacks when large numbers of cross-sectional observations are introduced in the model. A large number of cross-sectional observations require large number of dummy variables to represent each cross-sectional observation. Introducing many dummy variables into the model reduces the degrees of freedom for statistical testing. In addition, the introduction of too many dummy variables in the model might create multi-collinearity problem which makes difficult for precise estimation of one or more parameters (Gujarati, 2003). 
All fifty five West Virginia counties are considered in this study. In order to avoid significant decline in the degree of freedom estimation, counties are geographically categorized into five regions; eastern, western, northern, southern and central. Eastern region comprises of eleven counties (Berkeley, Grant, Hampshire, Hardy, Jefferson, Mineral, Morgan, Pendleton, Pocahontas, Tucker, Randolph), Western region constitutes ten counties (Cabell, Jackson, Kanawha, Lincoln, Mason, Putnam, Roane, Wayne, Wirt, Wood), Northern region comprises fifteen counties (Barbour, Brooke, Doddridge, Hancock, Harrison, Marion, Marshall, Monongalia, Ohio, Pleasants, Preston, Ritchie, Tyler, Taylor, and Wetzel), Southern region constitutes eleven counties (Mingo, McDowell, Mercer, Wyoming, Logan, Boone, Fayette, Raleigh, Summers, Monroe, and Greenbrier), and Central region comprises eight counties (Braxton, Calhoun, Clay, Gilmer, Lewis, Nicholas, Upshur, Webster)

Using Ordinary Least Square method, both pooled (restricted approach) and fixed effect (unrestricted approach) static and dynamic models are estimated. To determine which model, restricted or unrestricted, fits the panel data better, a restricted $F$ test is employed. Using this test, it is found that the fixed effect model with regional dummies is statistically significant for both static and dynamic models as indicated in Appendix A-1 and A-2, respectively.

Pooled data provide more information, efficiency, degrees of freedom, and more variability compared to the uncombined cross-section and time series observation (Gujarati, 2003). However, since the pooled data involve both the cross-section and time dimensions, statistical problems such as heteroscedasticity due to cross-section observations and autocorrelation due to time series observations are more likely to exist. 
There are many ways of detecting the presence of heteroscedasticity in the empirical results. Very often, the nature of the observations suggests whether or not heteroscedasticity is likely to encounter. In cross-sectional data involving heterogeneous units, heteroscedasticity is a rule rather than an exception (Gujarati, 2003). White's General Heteroscedasticity Test is used to detect the presence of heteroscedasticity for both estimations. The result significantly indicated the presence of heteroscedasticity (See Appendix C).

There are numerous ways of correcting for heteroscedasticity problem. For the purpose of this research, the heteroscedasticity-corrected standard error method is used. This technique will correct the standard error without altering the estimated coefficients. Since the problem of heteroscedasticity is decreasing the efficiency of the estimation model without creating bias on the estimated coefficients, correcting for heterosedasticity will provide more accurate standard error; therefore improve standard error estimation of coefficients. All empirical results reported in Tables C-1 and C-2 are reported after correcting for heterosedasticity.

Another statistical problem that commonly exists in pooled data is autocorrelation. The nature of the observations may suggest the presence of autocorrelation. One of the methods of detecting the presence of autocorrelation is using the Durbin Watson $(d w)$ statistic reported along with other econometric software outputs. The $d w$ for static model estimation suggests that there is autocorrelation problem. However, $d w$ is not a good indicator of the presence of autocorrelation when the model includes lagged explanatory variables (see Table D-1). Breusch-Godfrey test is applied to 
detect the presence of autocorrelation in the dynamic model. The empirical results indicated that there is serial correlation problem as showed in Table D-2.

One problem with autocorrelation is that it increases the standard error of the estimates and as a result the estimates will be inefficient, even though estimated coefficients remain unbiased. Correcting autocorrelation improves efficiency of the estimation.

The presence of multi-collinearity is also examined using Pair Wise Correlation Matrix. Pair Wise estimation for static and dynamic model is reported in Appendix B. Estimates in the presence of multi-collinearity remain unbiased, however, the variance and the standard errors increase, as a result, the probability of obtaining the estimated coefficient significantly different from the true estimate is high (Gujarati, 2003). One of the recommended solutions is dropping highly correlated variables or "doing nothing".

In the static model, the Pair-Wise correlation matrix doesn't indicate is the existence of a serious multi-collinearity problem. However, in the dynamic model, when one period lag is introduced, some variables show high correlation with their lag, but the signs of the coefficients were as expected. Since lagged variables are important in controlling sluggish adjustments of the economy, and since most of the signs are theoretically consistent, no variable is dropped.

However, when two periods lagged variables are included in the model, very high correlation is evidenced between current and lagged variables and resulted in a poor fit. Most of the coefficient estimates exhibit unexpected and theoretically inconsistent results. As a result of the serious multi-collinearity problem, estimation of the dynamic model is restricted to only one period lags. 


\subsection{RESULTS AND ANALYSIS}

\subsubsection{Static Model Results}

The estimated coefficients of the static model are presented in table 5.1. The adjusted Rsquare indicates that 74.6 percent of the variation of the static model is explained by the explanatory variables specified in the model.

The empirical result indicated that unemployment rate (UEMPR) is positively related with FSP. The coefficient is significant at 1 percent significance level. A one unit increase in unemployment growth rate is expected to increase FSP participants by 0.42 percent, holding other explanatory variables constant. FSP participation is responsive to the change in county's unemployment rate; therefore, FSP participation level is expected to increase in counties with high unemployment rate and decrease in counties with low unemployment rate. This result verifies the hypothesis that an increase in unemployment rate increases FSP participation levels, and vice versa.

Employment growth rate (EMPGR) has no significant effect on FSP. This result contradicts with the stated hypothesis that an increase in employment decreases FSP participation. The result indicates that people might use FS despite the fact that employment opportunities are expanding. There might be a number of possible explanations for the result. The expansion of employment in the counties might create employment opportunities for the working poor and increase their earnings. However, income growth might be very marginal that they are still qualified to participate in the FSP. 
Table 5.1. Static Model Empirical Results

\begin{tabular}{llc}
\hline Variables & Description of Variables & Coefficients \\
\hline CTEMP & Change in Total Employment & -0.466 \\
UEMPG & Unemployment Growth Rate & $(0.299)$ \\
& & $0.4200^{* * *}$ \\
CPCPI & Change in Per-capita Income & $(0.138)$ \\
& & -0.2399 \\
POV & Percentage of Poverty & $(0.356)$ \\
& & $0.8289^{* * *}$ \\
CPI & Consumer Price Index & $(0.784)$ \\
& & 0.3152 \\
PROWRA & Personal Responsibility and Work & $(0.297)$ \\
& Opportunity Reconciliation Act & -0.5177 \\
GOV & Political Affiliation of Governor & $(1.956)$ \\
& & -0.6039 \\
RD2 & Region 2 & $(0.756)$ \\
& & $3.8610^{* * *}$ \\
RD3 & Region 3 & $(0.947)$ \\
& & 0.4659 \\
RD4 & Region 4 & $(0.372)$ \\
& & $1.1667 * *$ \\
RD5 & Region 5 & $(0.515)$ \\
Trend & & $2.3968 * * *$ \\
& Time & $(0.661)$ \\
& & -1.5978 \\
& & $(1.110)$ \\
& & -49.9097 \\
Constant & & 0.746
\end{tabular}

\begin{tabular}{ll}
\hline Adjusted $R^{2}$ & 0.746 \\
\hline$* * *$ and $* *$ denotes level statistical significance at 1 percent and \\
at 5 percent respectively. Values in the parenthesis denote standard errors.
\end{tabular}

The type of jobs created in the economy could also determine who would be employed. The expansion of employment might be concentrated in certain sectors which might need highly skilled and educated people. The economic expansion might create very little employment opportunities in some sectors such as construction, retailers and agriculture where most of the unskilled and uneducated labor might get a job. Therefore, even if employment opportunities expand, existing FSP participants still continue participating in the program or new people might enter in the FSP. 
The other possible explanation is with regard to the composition of household participants. The significant proportion of participants in the FSP might be single-parent headed household, senior citizens, disabled, or able-bodied individuals with dependent in which a work requirement is not applicable for their participation and therefore the expansion of the economy might not significantly affect their participation.

Dependence on the welfare program could also be a possible explanation. In this case, participants might calculate the benefit of working more hours and increasing income against losing FS benefit and other welfare benefits as FSP participants could also be beneficiaries of other welfare programs. Thus, an increase of income due to working long hours or having multiple jobs not only affects their eligibility in the FSP or amount of FS benefit, but also affects participation in other welfare programs. Therefore, if the increase in income is marginal and still make them disqualified for FSP participation and other welfare programs or lowers their benefit level, participants might not desire to work after certain income level. However, the above possible explanations are not supported by the data and statistical evidences.

Change in per-capita personal income (CPCPI) has an insignificant relationship with FSP. This result is different from the hypothesis that county level income growth will decrease FSP participation. County per-capita income is used as a proxy for FSP participants' income. This result is unexpected, as more FSP participation is expected with falling incomes. The result shows that income increase does not guarantee life out of food insecurity. This suggests that increase in income of low income working households is very minimal that they still need food assistance. The increase in income might not be proportional for all of the households in the county. The rate of growth of income for 
certain group of people might be higher and the rate would be low or constant for low income families. In this case, even if county income increases, it doesn't have significant impact on participation.

Poverty (POV) has the expected positive effect on FSP. It is statistically significant at 1 percent level. An increase in county's population living in poverty by one percent is expected to increase the FSP participants by 0.82 percent, ceteris paribus. This direct relationship may indicate that the distribution of poverty across counties affects the distribution of FS beneficiaries across counties. This result supports the hypothesis that poverty has a direct relationship with FSP participation.

The cost of living was expected to affect the decision of eligible participants to increase their participation. The consumer price index (CPI) is used as the proxy for the cost of living. The result indicates that the effect of CPI on FSP participation decision, after controlling for the other factors, is statistically insignificant. This indicates that during the study period in West Virginia, change in cost of living has no significant role in determining the FSP participation decision of eligible households. This result does not support the hypothesis that FSP participation and the cost of living are directly related.

Different policy changes may affect FSP participation and the potential effect of policy changes are likely to vary considerably across different types of households or individuals. The introduction of Personal Responsibility and Work Opportunity Reconciliation Act (PRWORA) is expected to reduce FSP participation at least for two groups: non-citizens and able-bodied individuals without children between the ages of 18-49. However, PRWORA is found to be statistically insignificant indicating that FSP participation is not systematically different before and after the introduction of PRWORA 
in West Virginia. Even though demographic variables are not included in the model, the result might suggest something about the characteristics of food stamp recipients in West Virginia. FSP participants might be composed of group of individuals or households who are able-bodied individuals without dependents that fulfill the work requirement but their income is very low to make them eligible and participate in the program. Moreover, it might suggest that FSP participants could also be comprised of able-bodied individuals with dependent, senior citizens or disabled individuals that the policy didn't influence or limit their eligibility. Similarly, the proportion of immigrant FSP participants might be very low that the termination of their benefit does not change the overall participation. However, these arguments can be supported better with detailed demographic data that accounts for demographic information. In general, the result does not support the hypothesis that PRWORA policy helps in reducing FSP participation.

Following similar researches, the political variable (GOV) is included in the model to control people's attitude that may have an effect on FSP participation. Based on the result of previous researches, it is expected that if Democratic governor comes to office, more people participate in the FSP. However, the finding shows that there is no statistically significant relationship between FSP and the political affiliation of governors in office. The result suggests that political affiliation of the governor might not be one of the factors that affect FSP participation decisions.

RD2, RD3, RD4 and RD5 represent dummy variables of Western region, Northern region, Southern region and Central region, respectively. The Eastern region (RD1) is considered as a base region. The percent of the people participating in FSP in Western (RD2), Southern (RD4), and Central (RD5) regions are significantly higher than 
percentage of FSP participants in the Eastern (RD1) region. FSP participation in Western and Central region is statistically significant at 1 percent level and southern region at 5 percent level respectively. As compared to Eastern region, FSP participation in Western region is higher by 3.86 percent, keeping other variables constant. Similarly, FSP participants in Southern and Central regions are higher than the Eastern region by 1.16 and 2.39 percent, ceteris paribus, respectively. However, the dummy variable that represents Northern region FSP is not significant, meaning there is no significant FSP participation difference between Northern and Eastern regions. The fast economic expansion of the Eastern region (Eastern panhandle) could be one of the factors contributing to the higher level of FSP participation in the rest of the regions as compared to the Eastern region.

The coefficient of the trend variable is negative and statistically insignificant. The trend variable is introduced to isolate increasing or decreasing FSP participation trends from the data and measure the remaining independent variables' relationship with the dependent variable more accurately. The result reveals that there is no systematic trend in FSP participation in the study period.

\subsubsection{Dynamic Model Results}

The dynamic model explains variations in FSP by the explanatory variables of lagged and current change in total employment (LG1CTEMP and CTEM ), lagged and current unemployment rate (LG1UEMPG and UEMPG), lagged and current change in per-capita personal income (LG1CPCPI and CPCPI), lagged and current poverty (LG1POV and POV), lagged and current consumer price index (LG1CPI and CPI), dummy variables for 
Personal Responsibility and Work Opportunity Reconciliation Act (PRWORA), governors political affiliation (GOV), and the lag change in dependent variable (LG1CFSP). This specification explains 75.7 percent of the variation in FSP. The estimated coefficients are given in Table 5.2.

Current unemployment rate (UEMPG) is positively and significantly related with FSP participation. A one unit increase in the county unemployment rate is expected to increase FSP participation by 0.35 percent. The result suggests that people instantly participate in the program in adverse economic situations. This result is robust and consistent with the result of the static model. Counties with high unemployment rates are expected to have a high percentage of people participate in the FSP. However, one-period lagged unemployment rate (LG1UEMP) is statically insignificant. The result suggests that current employment growth is responsive to FSP participation without taking long time. Similar to the static model, the hypothesis that unemployment rate has a direct relationship with FSP participation is statistically supported. However, the relationship with lagged unemployment rate is not also supported.

Similar to the findings in the static model, employment change (CTEMP) has no significant effect on FSP participation. Similar explanation as the static model can hold true in this case too. However, one-period lag change in total employment (LG1CTEMP) has significant influence on FSP participation. Employment change in current period may not have immediate effect on the same period of FSP participation. However, employment growth in the past period would significantly reduce FSP participation in the current period. The hypothesis that FSP has an inverse relationship with employment 
growth is not supported by the statistical results. However, lagged employment growth has a significant and indirect relationship with FSP participation.

Table 5.2 Dynamic Model Empirical Results

\begin{tabular}{|c|c|c|}
\hline Variables & Description of Variables & Coefficients \\
\hline CTEMP & Change in Total Employment & $\begin{array}{l}-0.649 \\
(0.235)\end{array}$ \\
\hline UEMPG & Unemployment Growth Rate & $\begin{array}{c}0.350^{* * *} \\
(0.144)\end{array}$ \\
\hline CPCPI & Change in Per-capita Income & $\begin{array}{l}-0.386 \\
(0.341)\end{array}$ \\
\hline POV & Percentage of Poverty & $\begin{array}{c}0.177 \\
(0.151)\end{array}$ \\
\hline CPI & Consumer Price Index & $\begin{array}{c}1.168 * * * \\
(0.395)\end{array}$ \\
\hline PRWORA & $\begin{array}{l}\text { Personal Responsibility and Work Opportunity } \\
\text { Reconciliation Act }\end{array}$ & $\begin{array}{l}-7.713 * * * \\
(2.883)\end{array}$ \\
\hline GOV & Political Affiliation of Governor & $\begin{array}{l}-2.025^{*} \\
(1.147)\end{array}$ \\
\hline LG1CTEMP & One Period Lag Change in Total Employment & $\begin{array}{l}-0.494^{*} \\
(0.295)\end{array}$ \\
\hline LG1UEMP & One Period Lag Unemployment Growth Rate & $\begin{array}{c}0.510 \\
(0.110)\end{array}$ \\
\hline LG1CFSP & One Period Lag FSP & $\begin{array}{l}-0.448 \\
(0.408)\end{array}$ \\
\hline LG1CPCI & One period Lag Change in Per-capita Income & $\begin{array}{l}-0.436 \\
(0.372)\end{array}$ \\
\hline LG1POV & One Period Lag of Percentage of Poverty & $\begin{array}{c}0.636^{* * *} \\
(0.143)\end{array}$ \\
\hline LG1CPI & One Period Lag Consumer Price Index & $\begin{array}{c}1.034^{* * * *} \\
(0.221)\end{array}$ \\
\hline RD2 & Region 2 & $\begin{array}{c}3.607 * * * \\
(0.915)\end{array}$ \\
\hline RD3 & Region 3 & $\begin{array}{c}0.321 \\
(0.361)\end{array}$ \\
\hline RD4 & Region 4 & $\begin{array}{l}1.042 * * \\
(0.508)\end{array}$ \\
\hline RD5 & Region 5 & $\begin{array}{c}2.021 * * * * \\
(0.593)\end{array}$ \\
\hline $\begin{array}{l}\text { Trend } \\
\text { Constant }\end{array}$ & Time & $\begin{array}{c}-9.145 * * * \\
(2.227) \\
-183.677\end{array}$ \\
\hline Adjusted $R^{2}$ & & 0.757 \\
\hline
\end{tabular}


Both current and one-period lagged per-capita personal income (CPCPI and LG1PCPI) are not significant in determining FSP participation. The same explanation given in the static model also applies here.

Current FSP participation is negatively and insignificantly related with its oneperiod lagged FSP (LG1CFSP). It was expected that, holding other things constant, last period FS participants are more likely to participate in current period too. However, the results indicate that last period FSP participants may not likely participate in current period. The result suggests about the length of time that FSP participants stay in the program and the frequency of entrance and exit in the program. However, questions such as how frequently households participate in FSP and how long they stay in the program could not be explained by the data set the study relies on.

The result indicates that LG1POV directly and positively influence FSP participation. It is statistically significant at 1 percent level. As last period's percentage of people live in poverty increase by 1 , the percentage of people that participate in FSP increases by 0.64 . However, the finding indicated that current level of poverty (POV) does not have an impact on current FSP participation. This finding is unexpected and inconsistent with static model result. The dynamic model supports the hypothesis that there is a direct relationship between poverty and FSP participation, but only if poverty is a lagged variable.

Unlike the static model the policy variable of PRWORA is found to be statistically significant and has inverse relationship with FSP participation in this model. FSP participation is found to be systematically different before and after the introduction of PRWORA in West Virginia. The introduction of PRWORA affects participation of 
some group of people significantly and leads to the decline of FSP participation. However, due to unavailability of demographic data which group of people's participation is affected more is not known. This result is consistent with the national trend of the impact of PRWORA policy on FSP participation. Unlike the static model, the dynamic model supports the hypothesis that PRWORA has an inverse relationship with FSP participation.

The finding indicates that the relationship between FSP participation and the coming of Democrat governor in the office is negative and statistically significant at 10 percent. This might be related to the introduction of PRWORA in 1996 and its implication on the change of eligibility of certain group of people. As discussed in the chapter 2, the introduction of PRWORA led to an unprecedented decline in FSP participation nationwide by limiting benefit for some group of people. Similarly the finding of this study indicated that FSP participation in West Virginia also declined after the introduction of PRWORA. Based on the previous experience of restrictive eligibility requirement and prohibition of certain groups that came with the introduction of PRWORA, people might associate what has happened during the Clinton administration with the coming of Democrat governor. People, therefore, might perceive that eligibility criteria would be very restricted and might decide not to participate or exit the FSP.

Dummy variables that represent Western, Southern and Central regions are found to be statistically significant. This indicates that the percentage of FSP participation in Western, Southern and Central regions was higher as compared to percentage of FSP participation in Eastern region (the base of comparison). The percentage of FS participants in Western region is higher by 3.6, ceteris paribus, than the percentage of 
participants in Eastern region. Similarly, percentages of FS participants in Southern and Central regions are higher by 1.04 and 2.02, ceteris paribus, respectively as compared to the Eastern region. The result also shows that the dummy variable that represents northern region is not significant; indicating that participation rates in northern West Virginia is not statistically different from the base region. These results reveal the existence of significant differences in food stamp participation patterns in different regions of West Virginia. This conclusion is supported by the static model results as well and the explanation provided in the static model also applied in this model too.

Unlike the static model, the trend variable is statistically significant in the dynamic model. This indicates that FSP participation has been decreasing through time. The inclusion of trend variable controls for systematic decrease of FSP participation throughout the period under consideration. 


\section{CHAPTER 6}

\section{SUMMARY AND CONCLUSION}

\subsection{SUMMARY AND CONCLUSION}

In this study, the empirical analysis of county FSP patterns is introduced using static and dynamic econometric models. The results of these models on county socio-economic and policy explanatory variables are also discussed. The general findings of the study can be summarized as follows:

- County poverty levels affect the degree of county dependence on FSP. A rise in county poverty results in an increase in FSP participation.

- The distribution of economic opportunities affects county level FSP participation. A rise in current and lagged county unemployment rate increases the degree of dependence on food stamp programs. In contrary, lagged employment growth tends to decrease FS dependence.

- Both lagged and current county income growth does not seem to deter people from benefiting from the FSP.

- The cost of living in general affects participation decision in county welfare programs. Increase in lagged consumer price index, measuring a rise in the cost of living, is associated with increasing dependence in county FSP participation.

- Welfare program policies can have impacts in terms of flow of county welfare participants. PRWORA (Personal Responsibility and Work Opportunity Reconciliation Act) policy aims at limiting food stamp benefits to certain 
beneficiary groups. Based on the dynamic model result, this policy is associated with reduced food stamp participants in West Virginia.

- Political affiliation of governors is another policy factor considered. Based on the dynamic model result, unlike findings from previous studies, degree of FSP participation decreased during Democrat governors' period.

- There are differences on food stamp program participation levels across different regions in West Virginia. A region specific participation comparison indicates that significant regional differences in degree of FSP participation.

Based on the above general results in this study, it is possible to note the following:

- It is important to conduct detail study about the demographic characteristics of people who live in poverty. Understanding the characteristics of the poor such as their employment status and age, help to design a policy that might have a long term impact for different groups. Likewise, it is important to understand FSP participation rate to determine whether the program has been safety net for the majority of the poor households.

- It is also important to understand and identify the skill composition and educational level of low income households and design policies to attract such job where these people can be absorbed in the job market and ultimately improve their wellbeing.

- Finally, it is important to reach out to eligible households by conducting outreach programs to provide information and change the perception of relationship between eligibility and the county or state political situation. 
Therefore, based on the above results and conclusions, it is recommended that:

First, county level determinants of FSP tend to be long term economic indicators, like poverty and income growth. As such, policies that aim at addressing welfare programs in general and FSP in particular, may better address welfare dependence by designing longterm programs that mitigate the long-term economic parameters of poverty, income, unemployment, and employment growth.

Second, not only is addressing long-term economic problems important to reduce long-term welfare dependence, but also understanding the distribution of economic variables is crucial. Though knowing the level of poverty, for instance, is helpful in tackling welfare dependence, understanding its cross-county distribution may help prioritize welfare funds and allocation of capital to tackle this problem in a systematic manner.

Third, the significant regional differences in FSP participation indicate the existence of difference in regional economic performance. Regional specific economic initiatives especially for economically stressed areas might be helpful in addressing the problem.

Fourth, the cost of living and political affiliation of governors could be important determinants of FSP. However, these are short-term parameters with perhaps limited impact compared to the deep-rooted long-term economic problems. As such, proper focus may be necessary in terms of addressing short-term participation triggering factors and balanced attention on long-term solutions that address the root cause of welfare program dependence. 


\subsection{LIMITATIONS AND SUGGESTIONS FOR FURTHER RESEARCH}

The main limitation of the study is the unavailability of data. Due to the emphasis of the study on the county level data, detailed economic variable information about FSP participant is not effectively captured. Moreover, due to lack of time-series demographic information, the relationship between FSP participation and demographic characteristics is not properly captured. The following can be suggested as areas further improvement.

Regional Interdependence: economic variables may have significant interdependence across counties. For instance, income growth in one county may affect the level of neighboring county. Therefore a spatial econometric model approach might be important to understand economic interdependence among counties.

Data: Aggregate economic and secondary data might not be a good measure of economic condition of specific. Thus conducting survey targeting specific groups might provide more accurate relationship and result. Moreover, expanding the time frame of the study may help estimate the relationship using advanced method of estimations. 


\section{REFERENCES}

America Community Survey Report. 2005. "Income, Earnings, and poverty, From the 2004 American Community Survey. Available at: http://www.census.gov/prod/ 2005pubs/acs-01.pdf

Banks, Adams B. 2003. "Explaining Participation Rates in the Food Stamp Program." Available at: http://www-econ.stanford.edu/academics/Honors_Theses/ Theses_2003/BanksAll.pdf.

Blank, R.M. 1997. “What Causes Public Assistance Caseload to Grow?” Working Paper No. 6343. Cambridge, MA: National Bureau of Economic Research.

Blaylock, J. R., \& Smallwood, D. M. 1984. “ Reasons for nonparticipation in the Food Stamp Program.” Western Journal of Agricultural Economics, 9(1) 117-126

Center on Budget and Policy Priorities (2001a): Background on the Food Stamp Program, Washington, D.C.

Coe, Richard D. 1986. "Nonparticipation in welfare program by eligible households: The case of the food stamp program. "Journal of Economic Issues, 17(4):1035-1056.

Cohen, B., Ohls, J., Andrews, M., Ponza, M., Moreno, L., Zambrowski, A., \& Cohen, R. 1999. "Food Stamp participants' food security and nutrient availability." Princeton, NJ: Mathematica Policy Research.

Council of Economic Advisors (CEA). 1997. "Explaining the Decline in Welfare Receipt, 1993-1996.” Technical Report, Washington, DC, Executive Office of the President of the President of the United States.

Cunnyngham, Karen.2004. "Trends in Food Stamp Program Participation Rates: 1999 to 2002." In Current Perspectives on Food Stamp Program Participation. U.S. Department of Agriculture, Food and Nutrition Service.

Cunnyngham, Karen and Beth Brown. 2004. "Characteristics of Food Stamp Households: Fiscal Year 2003." U.S. Department of Agriculture, Food and Nutrition Service,

Cushing, Brain and Cyntia Rogers. 1996. "Income and Poverty in Appalachia." SocioEconomic Review of Appalachia. Regional Research Institute, West Virginia University.

Danziger, Sheldon, ed. 1999. Economic Conditions and Welfare Reform. Kalamazoo, MI: Upjohn Institute. 
Deavers, Kenneth L. and Robert A. Hoppe. 1992. "Overview of the Rural Poor in the 1980s" pp.3-20. In the Cynthia Duncan (ed). Rural Poverty in America. Westport CT: Greenwood Publishing Group, Inc.

Dilger, Robert Jay and Tom Stuart Witt (eds.). West Virginia in the 1990's: Opportunities for Economic Progress. Morgantown, West Virginia University Press.

Figlio, D.N, C. Gunderson and J.P.Ziliak, 2000. "The Effects of the Macroeconomy and Welfare Reform on Food Stamp Caseload." American Journal of Agriculture Economics, Vol. 82, pp.635-41.

Fox, M. Key, William Hamilton and Biing-Hwan Lin. 2004. "Effects of Food Assistance and Nutrition Programs on Nutrition and Health: Volume 4, Executive Summary of the Literature Review." Economic Research Service, U.S. Department of Agriculture. Food Assistance and Nutrition Research Report No. 19-4.

Frazao, Elizabeth, and Jane E. Allshouse. 1996. " Size and Growth of the Nutritionally Improved Food Market.” USDA, Economic Research Service.

Gleason, P., P. Schochet and R. Moffitt. 1998. " The of Food Stamp Participation in the Early 1990s." U.S. Department of Agriculture, Food and Nutrition Service.

Gleason, Phillip, Peter Schochet, and Robert Moffitt. 2000. "The Temporals of the Food Stamp Program in the Early 1990s. Report submitted to the U.S Department of Agriculture, Food and Nutrition Service. Princeton NJ, Mathematica Policy Research, Inc.

Grogger, J. 2001. "The Effects of Time limits and Other Policy Changes on Welfare use, Work, and Income among Female-Headed Families.” NBER Working Paper No. W8153.

Gujarati D.N., 2003. Basic Econometrics. Tata McGraw-Hill, New York.

Gundersen, Craig, and Victor Oliveira. 2001. "The Food Stamp Program and Food Insufficiency," American Journal of Agricultural Economics 83(4):875-87.

Hanson, Kenneth and Elise Golan. 2002. "Effects of Changes in Food Stamp Expenditures Across the U.S. Economy." USDA, Economic Research Service

Hanson, Kenneth and Craig Gundersen. 2002. "How Unemployment Affects the Food Stamp Program." U.S. Department of Agriculture, Food Assistance and Nutrition Research Report No. 26-7. 
Haynes, Ada F. 1996. "Poverty in Central Appalachian: Underdevelopment and Exploitation." New York: Garland Publishing, Inc.

Huffman, S.K and Helen H. Jensen. 2003. "Do Food Assistance Programs Improve Household Food Security? Recent Evidence from the United States." Working Paper 03-WP 335, Center for Agricultural and Rural Development, Iowa State University.

Hurst, E., M. Luoh, and F. Stafford. 1998. "Wealth Temporals of American Families 1984-1994.” Brookings Papers on Economic Activity. Part I, pp.267-329.

Jacobson, Jonathan and Loren Puffer. 2000. "The Consequences of Economic Changes for the Food Stamp Program: Illustration from Microsimulation." Report submitted to the U.S Department of Agriculture, ERS, Washington, DC , Mathematica Policy Research, Inc.

Jacobson, J., N. Rodriguez-Planas, L .Puffer, E. Pas and L. Taylor-Kale. 2001. "The Consequence of Welfare Reform and Economic Change for the Food Stamp Program-Illustrations from Microsimulation" Final Report, ERS E-FANRR No. 01-003, pp98.

Jensen, H. Helen. 2002. "Food Insecurity and the Food Stamp Program." American Journal of Agricultural Economics, Vol. 84 Issue 5.

Jolliffe, Dean, Craig Gundersen, Laura Tiehen and Joshua Winicki. 2005. "Food Stamp Benefits and Child Poverty." American Journal of Agricultural Economics, Vol. 87, No. 3, pp. 569-581.

Kim, Marlene and Thanos Mergoupis. 1997. "The Working Poor and Welfare Recipiency: Participation, Evidence, and Policy Directions.” Journal of Economic Issues, Vol. 31.

Kornfeld, R. 2002. "Explaining Recent Trends in Food Stamp Program Caseloads.” U.S. Department of Agriculture, Economic Research Service, E-FAN-02-008, Washington, DC.

Kuhn, Betsey A., Pamela Allen Dunn, David Smallwood, Kenneth Hanson, Jim Blaylock, and Stephen Vogel. 1996."Policy Watch: The Food Stamp Program and Welfare Reform," Journal of Economic Perspectives, 10(2):189-98

Lerman, Robert I. and Michael Wiseman. 2002. "Restructuring Food Stamps for Working Families.” Washington, DC: Report to the Economic Research Service, The Urban Institute. 
Maggard, Sally W. 1990. "Schooling, Work Experience and Gender: The Social Reproduction of Poverty in Mining Regions." Research paper 9014, Regional Research Institute, WVU.

Martini, A. and M. Wiseman. 1997." Explaining the Recent Decline in Welfare Caseload: Is the Council of Economic Advisers Right?" Income and Benefits Policy Center, The Urban Institute, Washington, DC.

Mathematica Policy Research Inc. 2003. "Characteristics of Food Stamp Households, Fiscal Year 2001." USDA, Food and Nutrition Service, Office of Analysis, Nutrition and Evaluation. Food Stamp Program, Report no. FSP-03-CHAR02.

McConnell, Sheena and Michael Ponza. 1999. "The Reaching the Working Poor and Poor Elderly Study." Alexandria, VA: Food and Nutrition Service, USDA.

McKernan, A.M and Caroline Ratcliffe. 2003. "Employment Factors Influence Food Stamp Program Participation.” Food Assistance \& Nutrition Research Program, ERS, E-FAN-03-012.

Nord, Mark ,Margaret Andrews, and Steven Carlson. 2003. "Household Food Security in the United States, 2002.” Food Assistance and Nutrition Research Report No. FANRR35.

Nord Mark, Margaret Andrews, and Steven Carlson. 2005. "Household Food Security in the United States, 2004." USDA, Economic Research Service.

Pena, Manuel and Jorge Bacallao. 2002. "Malnutrition and Poverty", Annual Review of Nutrition, Vol. 22: 241-253

Ponza, M., J.C. Ohls, L.Moreno, A. Zambrowski, R. Cohen. 1999. “ Customers Service in Food Stamp Program." Final Report, 8243-140, Washington, D.C., Mathematica policy Research, Inc.

Rank, Mark and Thomas A. Hirschl. 2003. "Estimating the Probabilities and Patterns of Food Stamp Use across the Life Course”. JCPR Working Paper 327.

Ranney, Christine K. and John E. Kushman, 1987. "A Study of the Independent Food Stamp Program Particpation and Food Demand Decision." Giannini Foundation Research Report No. 336, Division of Agriculture and Natural Resources.

Rose, D. C., Gunderson, C., \& Oliveira, V. 1998. "Socio-economic determinants of food insecurity in the United States: Evidence from the SIPP and CSFII datasets." ERS Technical Bulletin No. 1869. Washington, DC: USDA.

The Food Assistance Landscape. 2005. Food Assistance and Nutrition Research Report Number 28-6, Economic Research Service, USDA. 
U.S. Census Bureau. 2000 a. "Poverty in the United State:1999". Current Population Reports (Series P60-210). U.S. Government Printing Office.

U.S. Census Bureau News. 2005. Available at: http://www.census.gov/PressRelease/www/releases/archives/income_wealth/005647.html.

U.S. Department of Agriculture, Food and Nutritional Service. 2000. "Characteristics of the Food Stamp program: Finical Year 1999.” Washington, DC: USDA.

USDA, Food and Nutrition Service. Available at: http://www.fns.usda.gov/fsp/faqs.htm.

Wallace, G., and R. Blank. 1999. "What Goes Up Must Come Down? Explaining Recent Changes in Public Assistance Caseload." Economic Conditions ad Welfare Reform, edited by S. Danziger. Kalamazoo, MI: Upjohn Institute. Pp. 48-84.

Weisbrod, B. 1970. "On the Stigma Effect and Demand for Welfare Programs: A Theoretical Note." Discussion Paper 82-70, Institute for Research on Poverty, University of Wisconsin, Madison.

West Virginia Economic Outlook 2001. 2001. Bureau of Business and Economic Research, College of Business and Economics West Virginia University.

West Virginia Economic Outlook 2002. 2002. Bureau of Business and Economic Research, College of Business and Economics West Virginia University.

West Virginia Economic Outlook 2003. 2003. Bureau of Business and Economic Research, College of Business and Economics West Virginia University.

West Virginia Economic Outlook 2004. 2004. Bureau of Business and Economic Research, College of Business and Economics West Virginia University.

West Virginia Economic Outlook 2005. 2005. Bureau of Business and Economic Research, College of Business and Economics West Virginia University

Wilde, P., P. Cook, C. Gundersen, M. Norad and L. Tiehen . 2000. "The Decline in Food Stamp Program Participation in the 1990's." U.S. Department of Agriculture, Economic Research Service, Food and Rural Economics Division, Food Assistance and Nutrition Research Report No. 7.

Wilde, Parke.2001. "Strong Economy and Welfare Reform Continues to Drop in Food Stamp Rolls, Welfare Reform and Food Assistance" Food Review, Vol 24, Issue 1.

Winicki, Joshua, Craig Gundersen, and Dean Jolliffe. 2002. "Assistance-How Do Food Assistance Programs Improve the Well-Being of Low-Income Families?" FANRR-26-9. 
Winship, Scott, and Christopher Jencks. 2002. "Changes in Food Security after Welfare Reform: Can We Identify a Policy Effect," unpublished manuscript, Harvard University.

Wooldridge J.M. 2006. Introductory Econometrics: A Modern Approach. Mason, OH: Thompson South-Western Publication,

Zedlewski, Sheila R. and Kelly Rader. 2004. “The Recent Trends in Food stamp participation: Have New Polices Made a Difference." National Survey of America's Families, Series B, No. B-58.

Zedlewski, Sheila and Sarah Brauner. 1999. "Are the Steep Decline in the Food Stamp Participation Linked to the Falling Welfare Caseloads?" National Survey of America's Families, Series B, No. B-3. The Urban Institute.

Ziliak, James P., Craig Gundersen, David N. Figlio . 2000. "Welfare Reform and Food Stamp Caseload Temporals" Institute for Research for Poverty, Discussion Paper No. 1215-00.

Ziliak, J.P., D.N. Figlio, E. Davis, and L.S Connolly. 1997. "Accounting for the Decline in AFDC Caseload: Welfare Reform or Economic Growth?" Discussion paper No. 151-97, Institute for Research on Poverty: Madison, WI.

Ziliak, James P., Craig Gundersen, and David N. Figlio. 2003. "Food stamp Caseloads over the Business Cycle." Southern Economic Journal, Vol. 69, No.4, pp 903-19. 


\section{Appendix A: Restricted $R^{2}$ Test}

Testing the significance of fixed effect.

$\mathrm{H}_{\mathrm{o}}$ : Restricted model is appropriate

$\mathrm{H}_{1}$ : Unrestricted model is appropriate

$$
F_{c a l}=\frac{\left(R_{L S D V}^{2}-R_{p o o l e d}^{2}\right) /\left(k_{\text {pooled }}\right)}{\left(1-R_{L S D V}^{2}\right) /\left(n T-k_{L S D V}\right)}
$$

Where $\mathrm{T}=$ the number of temporal observation

$\mathrm{n}=$ number of counties

$\mathrm{k}=$ number of parameters

\section{A. 1 Static Model}

$F_{\text {cal }}=6.56$ and $F=2.41 . F_{c a l}>F \cdot$.Rejected $\mathrm{H}_{0}$, therefore Fixed effect model is the valid model.

\section{A. 2 Dynamic Model}

$F_{c a l}=3.72$ and $F=2.04 . F_{c a l}>F$. Reject $\mathrm{H}_{0}$, therefore fixed effect model is the valid model.

Table A-1 Pooled Regression of Static Model

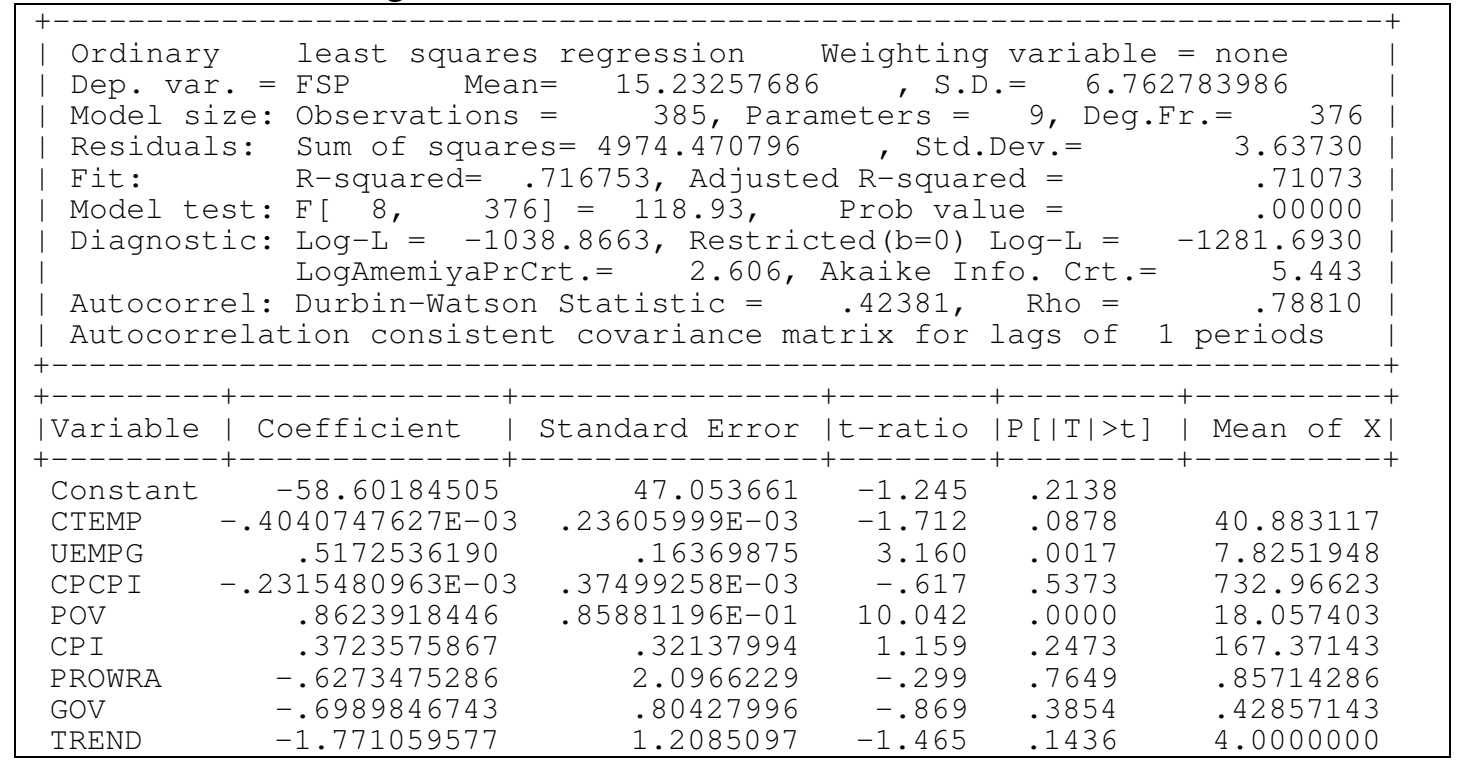


Table A-2 Fixed Effect Regression of Static Model

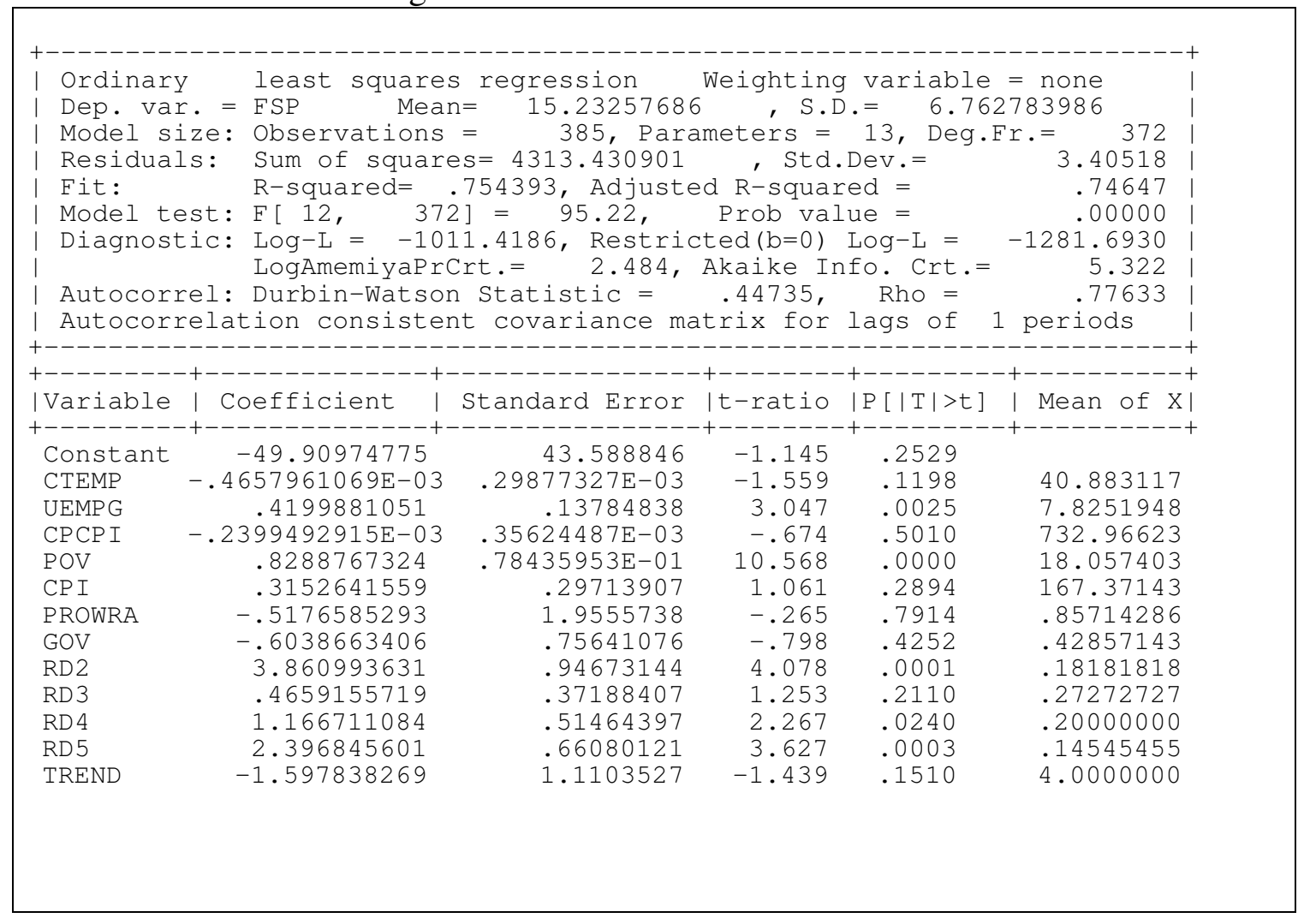


Table A-3 Pooled Regression of Dynamic Model

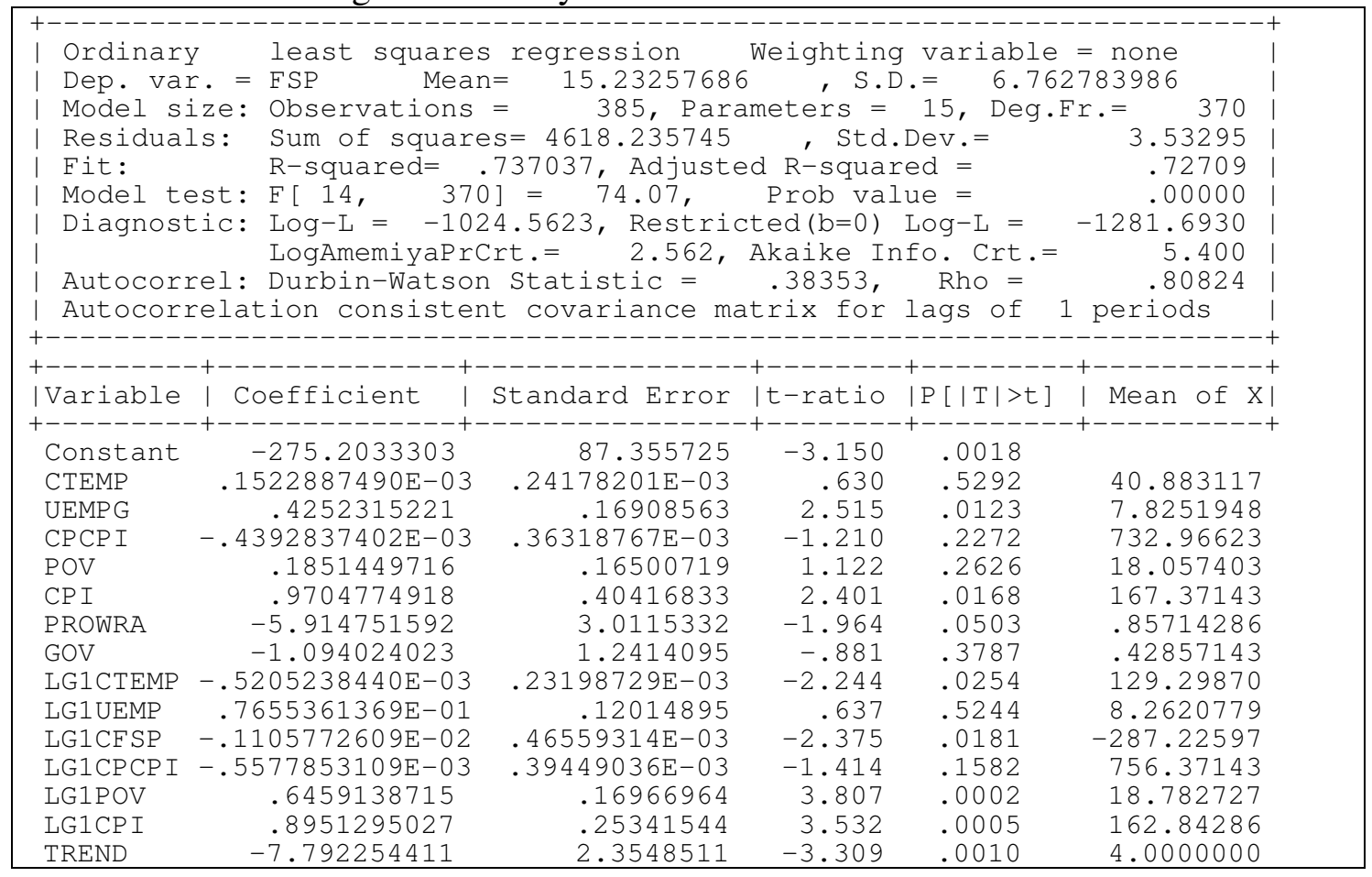


Table A-4 Fixed Effect Regression of Dynamic Model

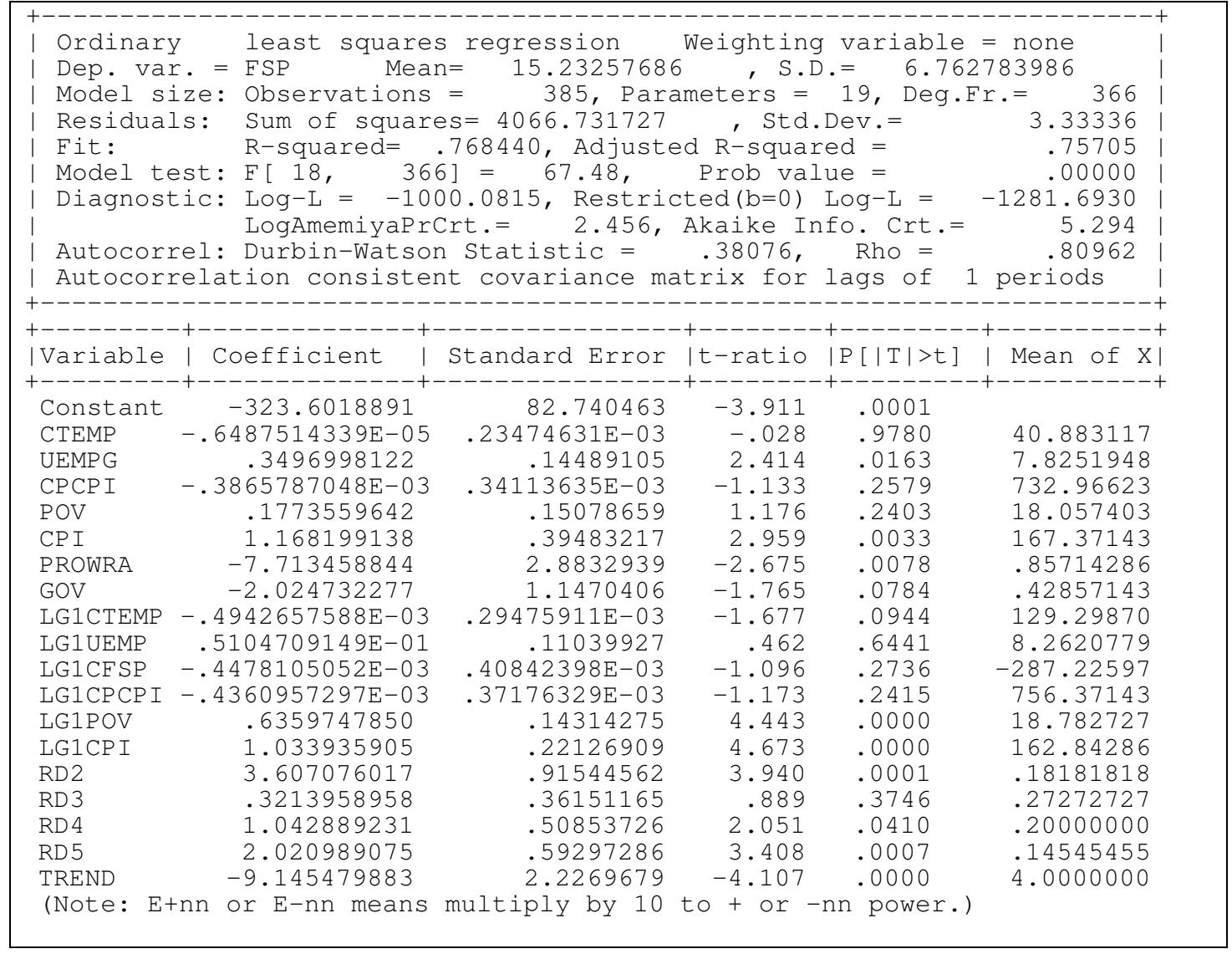




\section{Appendix B: Testing for Multicollinearity Using Pair-Wise Correlation}

Table B-1 Pair-Wise Correlation Matrix of Static Model

$\begin{array}{rrrrrr} & \text { UEMPG } & \text { CPI } & \text { POV } & \text { CTEMP } & \text { CPCPI } \\ \text { UEMPG } & 1.00000 & -.28898 & .62601 & -.18238 & -.39721 \\ \text { CPI } & -.28898 & 1.00000 & -.21989 & -.14884 & .20099 \\ \text { POV } & .62601 & -.21989 & 1.00000 & -.10624 & -.25284 \\ \text { CTEMP } & -.18238 & -.14884 & -.10624 & 1.00000 & .21371 \\ \text { CPCPI } & -.39721 & .20099 & -.25284 & .21371 & 1.00000\end{array}$

Table B-2 Pair-Wise Correlation Matrix of Dynamic Model Pair-Wise Correlation Matrix of Dynamic Model

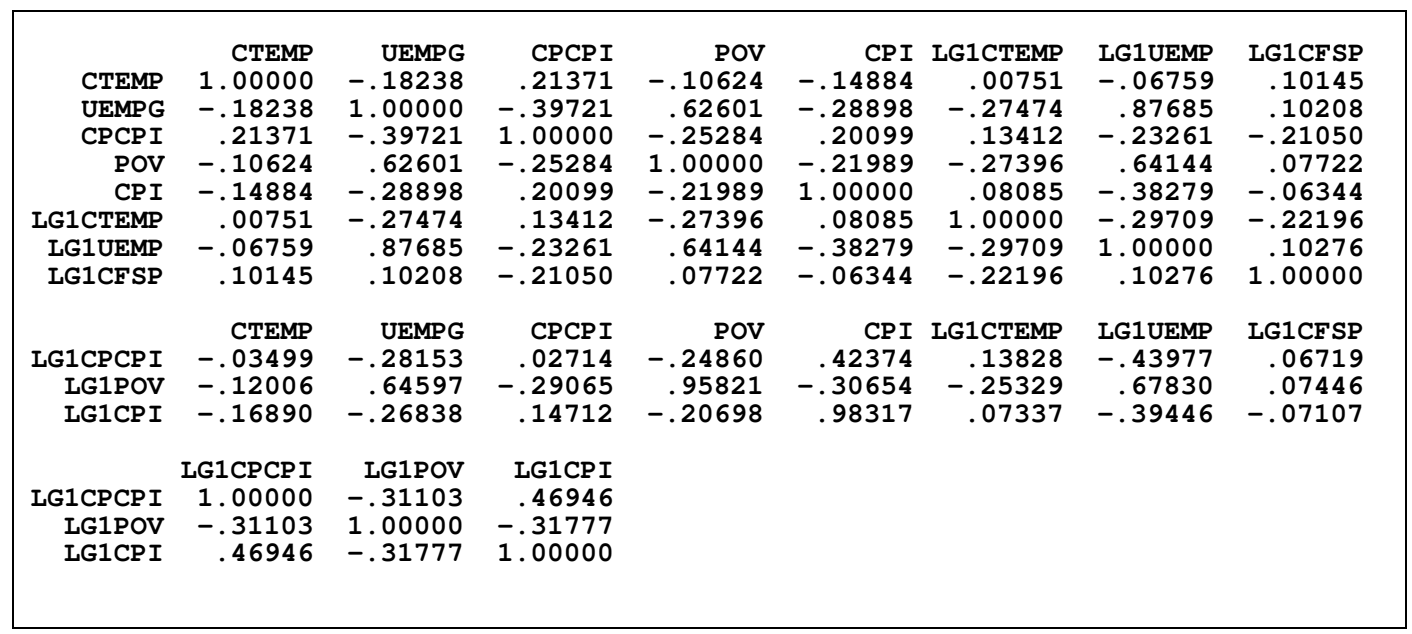




\section{Appendix C: Testing For Using White's Test}

Static Model White Test

Table C-1 Static Model White's Test

\begin{tabular}{|c|c|c|c|c|c|}
\hline \multicolumn{6}{|c|}{ 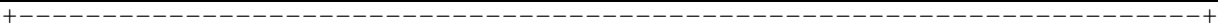 } \\
\hline \multicolumn{6}{|c|}{ Ordinary least squares regression $\quad$ Weighting variable = none } \\
\hline \multicolumn{6}{|c|}{ Dep. $\operatorname{var} .=$ ERSTASQR Mean $=11.20371663$, S.D. $=50.29516872$} \\
\hline \multicolumn{6}{|c|}{ Model size: Observations $=385$, Parameters $=21$, Deg.Fr. $=364$} \\
\hline \multicolumn{6}{|c|}{ Residuals: $\quad$ Sum of squares $=879522.5249$, Std.Dev. $=\quad 49.15558$} \\
\hline \multicolumn{6}{|c|}{ Fit: $\quad$ R-squared $=.094553$, Adjusted $R-$ squared $=\quad .04480$} \\
\hline \multicolumn{6}{|c|}{ Model test: $\mathrm{F}[20,364]=21.90, \quad$ Prob value $=\quad .01158$} \\
\hline \\
\hline \multirow{2}{*}{\multicolumn{6}{|c|}{ I Autocorrel: Durbin-Watson Statistic $=\quad .72934, \quad$ Rho $=\quad .63533$}} \\
\hline & & & & & \\
\hline \multirow{2}{*}{\multicolumn{6}{|c|}{ 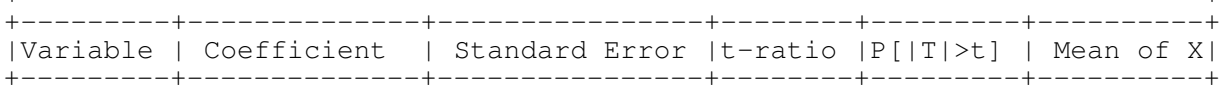 }} \\
\hline & & & & & \\
\hline \multicolumn{6}{|c|}{$\begin{array}{ccccc}\text { Constant } & 879.1616731 & 1184.0798 & .742 & .4583\end{array}$} \\
\hline UEMPG & 34.07206533 & 22.511665 & 1.514 & & 7.8251948 \\
\hline CPI & -12.20446239 & 13.792410 & -.885 & .3768 & 167.37 \\
\hline POV & 1.856202768 & 14.854041 & .125 & .9006 & 18.057403 \\
\hline CTEMP & $-.9406360421 \mathrm{E}-02$ & .17035844 & -.055 & 60 & 40.883117 \\
\hline CPCP I & $.2982167705 \mathrm{E}-01$ & .14717495 & .203 & .8395 & 732.96623 \\
\hline UEMP GSQR & .6196016417 & .33097161 & 1.872 & .0620 & 71.642571 \\
\hline CPISQR & $.3873155618 \mathrm{E}-01$ & $.40654219 \mathrm{E}-01$ & .953 & .3414 & 28093.914 \\
\hline POVSQR & .2296361721 & $.92597015 \mathrm{E}-01$ & 2.480 & .0136 & 351.98558 \\
\hline CTEMPSQR & $.1522805724 \mathrm{E}-05$ & $.27305144 \mathrm{E}-05$ & .558 & .5774 & 263903.90 \\
\hline CPCP ISQR & $.1893781697 \mathrm{E}-05$ & $.72666332 \mathrm{E}-05$ & .261 & .7945 & 777416.41 \\
\hline UEMPGCP I & -.1036054988 & .12592267 & -.823 & .41 & 1301. \\
\hline UEMP & 93147 & & -3.192 & & 151.5 \\
\hline UEMP CEMP & $-.3629074360 \mathrm{E}-02$ & .38683 & -.938 & .3488 & 18.59 \\
\hline UEMP CPCI & $.1523692692 \mathrm{E}-02$ & $309158 \mathrm{E}-02$ & .538 & & 5107.5 \\
\hline CP IPOV & $-.4217040739 \mathrm{E}-02$ & $.81686557 \mathrm{E}-01$ & -.052 & .9589 & 3012.2359 \\
\hline CP ICEMP & $.2297241400 \mathrm{E}-03$ & $.96109407 \mathrm{E}-03$ & .239 & .8112 & 6157.9039 \\
\hline CP ICPCP I & $-.5859084430 \mathrm{E}-04$ & $.81792170 \mathrm{E}-03$ & -.072 & .9429 & 123562.57 \\
\hline POVCEMP & $.2015873971 \mathrm{E}-03$ & $.23187613 \mathrm{E}-02$ & .087 & .9308 & 461.29610 \\
\hline POVCPCPI & $-.1751908852 \mathrm{E}-02$ & $.15973814 \mathrm{E}-02$ & -1.097 & .2735 & 12604.672 \\
\hline CEMPCPCI & $-.1319174921 \mathrm{E}-04$ & $.14638734 \mathrm{E}-04$ & -.901 & .3681 & 83598.390 \\
\hline
\end{tabular}

\section{$\mathrm{H}_{0}$ : Homoscedasticity}

$\mathrm{H}_{1}$ : Heteroscedasticity

$$
\mathrm{nR}^{2}=385^{*} .094553=36.40
$$

Critical value from chi-square distribution table for 20 degree of freedom (\# of right hand side repressors except the intercept) is 31.41.

Since $n R^{2}$ value of 36.40 is greater than the critical value of 31.41 , the null hypothesis of homoscedasticity is rejected indicating the existence of heteroscedasticity in the model . 
Table C-2 Dynamic Model of White's Test

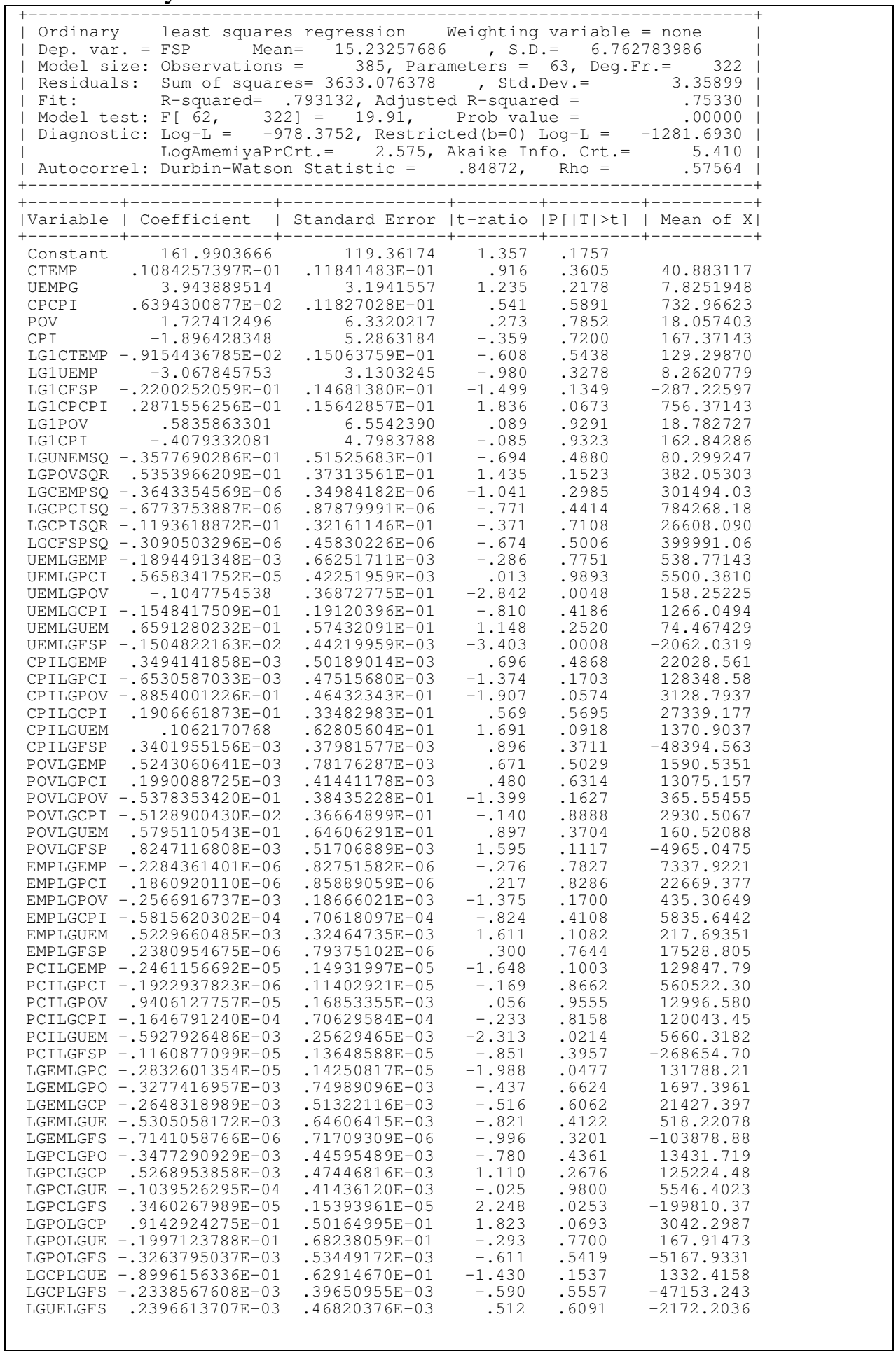


$\mathrm{H}_{0}$ : Homoscedasticity

$\mathrm{H}_{1}$ : Heteroscedasticity

$\mathrm{nR}^{2}=385^{*} .793132=305.356$

Critical value from chi-square distribution table for 63 degree of freedom (\# of right hand side repressors except the intercept) is $\approx 80$.

Since $\mathrm{nR}^{2}$ value of 305.356 is greater than the critical value of $\approx 80$, the null hypothesis of homoskedasticity is rejected indicating the existence of heteroscedasticity in the model. 


\section{Appendix D: Testing for Autocorrelation}

Table D-1 Static Model Fixed Effect Regression

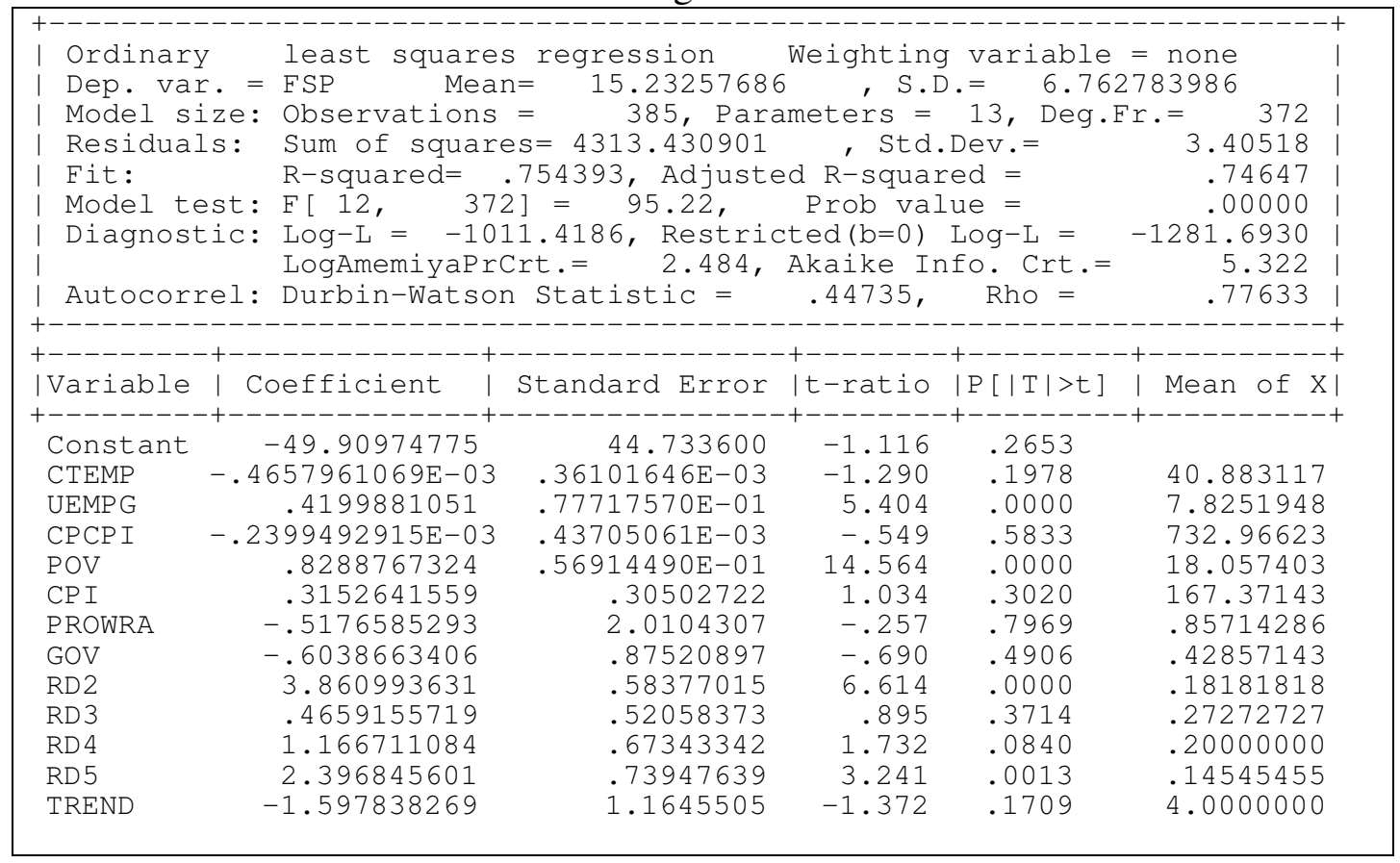

Durbin Watson method is used to test the presence of autocorrelation of the static model. The Durbin-Watson statistic from the above regression is 0.44735 .

For $\mathrm{n}$ (sample size) and k-1 (number of parameters), $\mathrm{d}_{\mathrm{L}}$ (lower bound) $\& \mathrm{~d}_{\mathrm{U}}$ (upper bound) values can be referred from the Durbin-Watson table.

The sample size is 385 . The $\mathrm{k}-1$ \# of parameter is $13-1=12$. The D-critical value is thus: $\mathrm{d}_{\mathrm{L}}$ (lower bound) $=1.69 \& \mathrm{~d}_{\mathrm{U}}$ (upper bound $)=1.82$.

Test the hypothesis:

$\mathrm{H}_{0}$ : no positive autocorrelation

Ha: positive autocorrelation exists

Since $\mathrm{d}=0.443735$ is less than $d_{L}=1.69$, it can be concluded that there is positive autocorrelation. 
Appendix D-2 Testing Autocorrelation using Breusch-Godfrey Test - Dynamic Model

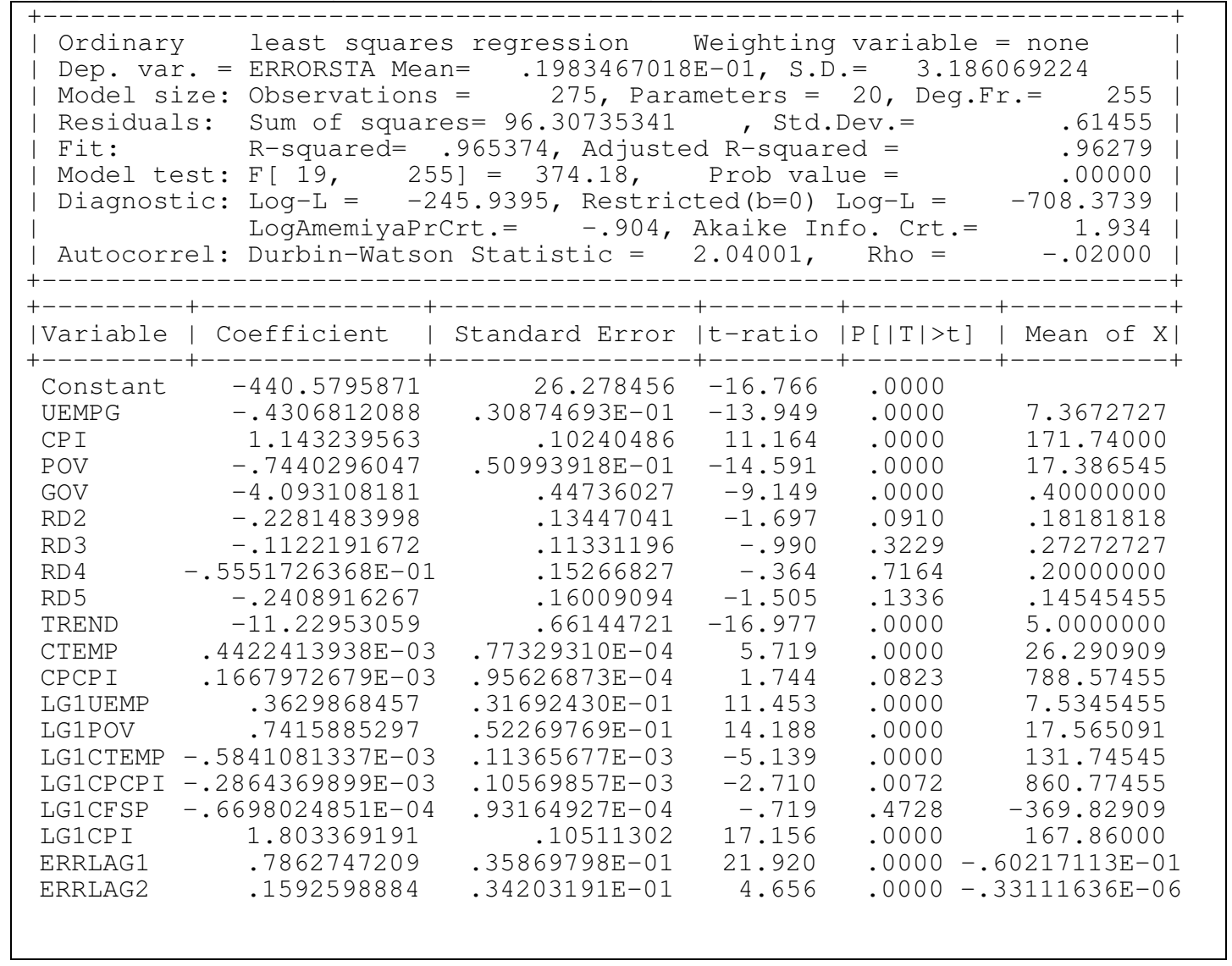

\section{Test hypothesis:}

Ho: All coefficients are zero (No autocorrelation)

Ha: All coefficients are not zero (There is autocorrelation).

Calculated statistics is given by:

$(n-p) R^{2}=(275-2) * \mathbf{0 . 9 6 5 3 7 4}=263.55$

Critical value from Chi-squared table for $\mathrm{p}=2$ degree of freedom at $0.01(1 \%)$ significance is: 9.21 .

Since calculated statistic of $263.55>$ critical value of 9.21 , it can be concluded that there is autocorrelation problem. 


\section{Appendix E: Descriptive Statistics}

Table E-1 Static Model Descriptive Statistics.

\begin{tabular}{lccccc}
\hline Variable & Mean & Std.Dev. & Minimum & Maximum & Cases \\
\hline FSP & 15.2325769 & 6.76278399 & 4.35233000 & 46.8138000 & 385 \\
CTEMP & 40.8831169 & 512.752732 & -4860.00000 & 3030.00000 & 385 \\
UEMPG & 7.82519481 & 3.23048049 & 2.10000000 & 23.1000000 & 385 \\
PCPI & 18890.5974 & 3639.84489 & 11665.0000 & 31923.0000 & 385 \\
POV & 18.0574026 & 5.09738020 & 8.60000000 & 37.7000000 & 385 \\
CPI & 167.371429 & 8.99607636 & 152.400000 & 179.900000 & 385 \\
PROWRA & .857142857 & .350382444 & .000000000 & 1.00000000 & 385 \\
GOV & .428571429 & .495515604 & .000000000 & 1.00000000 & 385 \\
RD2 & .181818182 & .386196488 & .000000000 & 1.00000000 & 385 \\
RD3 & .272727273 & .445941293 & .000000000 & 1.00000000 & 385 \\
RD4 & .200000000 & .400520495 & .000000000 & 1.00000000 & 385 \\
RD5 & .145454545 & .353017297 & .000000000 & 1.00000000 & 385 \\
\hline TREND & 4.00000000 & 2.00260247 & 1.00000000 & 1.00000000 & 385 \\
\hline
\end{tabular}

Table E-2 Dynamic Model Descriptive Statistics.

\begin{tabular}{lccccc}
\hline Variable & Mean & Std.Dev. & Minimum & Maximum & Cases \\
\hline FSP & 15.2325769 & 6.76278399 & 4.35233000 & 46.8138000 & 385 \\
CTEMP & 40.8831169 & 512.752732 & -4860.00000 & 3030.00000 & 385 \\
UEMPG & 7.82519481 & 3.23048049 & 2.10000000 & 23.1000000 & 385 \\
CPCPI & 732.966234 & 490.716177 & -1105.00000 & 2580.00000 & 385 \\
POV & 18.0574026 & 5.09738020 & 8.60000000 & 37.7000000 & 385 \\
CPI & 167.371429 & 8.99607636 & 152.400000 & 179.900000 & 385 \\
LG1CTEMP & 129.298701 & 534.338353 & -6550.00000 & 3030.00000 & 385 \\
LG1UEMP & 8.26207792 & 3.47399803 & 2.10000000 & 23.1000000 & 385 \\
LG1CFSP & -287.225974 & 564.197751 & -4683.00000 & 691.000000 & 385 \\
LG1CPCPI & 756.371429 & 461.219003 & -562.000000 & 2580.00000 & 385 \\
LG1POV & 18.7827273 & 5.41649262 & 8.60000000 & 37.8000000 & 385 \\
LG1CPI & 162.842857 & 9.51467382 & 148.200000 & 177.100000 & 385 \\
PROWRA & .857142857 & .350382444 & .000000000 & 1.00000000 & 385 \\
GOV & .428571429 & .495515604 & .000000000 & 1.00000000 & 385 \\
RD2 & .181818182 & .386196488 & .000000000 & 1.00000000 & 385 \\
RD3 & .272727273 & .445941293 & .000000000 & 1.00000000 & 385 \\
RD4 & .200000000 & .400520495 & .000000000 & 1.00000000 & 385 \\
RD5 & .145454545 & .353017297 & .000000000 & 1.00000000 & 385 \\
\hline TREND & 4.00000000 & 2.00260247 & 1.00000000 & 1.00000000 & 385 \\
\hline
\end{tabular}

